3 Research Square
Preprints are preliminary reports that have not undergone peer review.

They should not be considered conclusive, used to inform clinical practice, or referenced by the media as validated information.

\title{
Spatial Responses of Vegetation-Soil System to Complex Factors in a Sandy- Rocky Island Chain
}

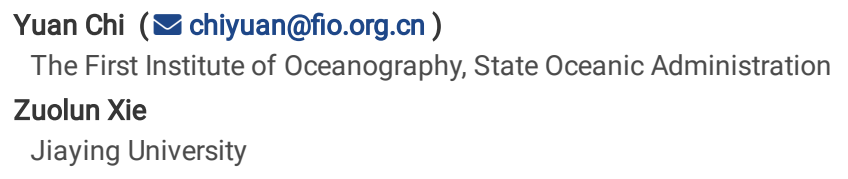




\section{Abstract}

The vegetation-soil system is fundamental to island ecosystem and changes considerably across sandy and rocky islands due to different natural and anthropogenic factors. An island chain, which is characterized by the coexistence of sandy and rocky islands, the connection of the islands by bridges, and complex influencing factors, was used as the study area. The vegetation-soil system was represented using different indicators and three newly-proposed indices, namely, vegetation health index (VHI), soil health index (SHI), and vegetation-soil system health index (VSSHI). The complex factors were identified in aspects of island basic factors, landscape pattern, terrain condition, and ecological indices. Then, the spatial responses of the system to the factors were analyzed at island and site scales. Results indicated that the vegetation-soil system showed similar and different responses to the complex factors across the dual scales. The similarity was represented by the higher sensitivities of VHI and VSSHI compared with that of SHI at both scales, and the difference mainly indicated that the influences of landscape pattern factors distinctly decreased along the scales from island to site. Island area, sea reclamation proportion, vegetation proportion, and natural ecosystem damaged index were the most important factors at island scale, while the ecological indices showed the highest influences at site scale. The study revealed the spatial characteristics of the vegetation-soil system across different types of islands, clarified the spatial responses of the system to complex factors at the dual scales, and identified the main influencing factors of the system.

\section{Introduction}

The island serves as an indispensable part for harboring unique biological resources and accounts for 3-3.6\% of the earth's land area (Weigelt et al., 2013). Vegetation and soil constitute the main body of island surface and are essential to the island ecosystem (Chi et al., 2017; Hattermann et al., 2018). The vegetation is the main producer and generates the fundamental material and energy for the other member in the island ecosystem; it represents the vitality and stability of the ecosystem and functions for biodiversity maintenance, habitat provision, freshwater conservation, wind pretention, soil fixation, and visual landscape (Chang et al., 2013; Médail et al., 2017; Borges et al., 2018; Chi et al., 2019a). The soil denotes the base of the island ecosystem; it provides the space, water, and nutrients for the survival and living of different types of organisms and involves various biogeochemical cycles (Ouyang et al., 1999; Grimm et al., 2008; Chi et al., 2018). The vegetation and soil are closely interrelated and interacted and they generally positively influence one another, thereby forming a vegetation-soil system (Li et al., 2018; Chi et al., 2019a). Meanwhile, the vegetation-soil system exhibits distinct spatial heterogeneity across islands and within an island due to different natural and anthropogenic factors (Médail et al., 2017; Chi et al., 2017, 2019a; Hattermann et al., 2018).

Rocky and sandy islands are two of the major types of islands according to the material constitution. Rocky islands are composed of different kinds of rocks that are higher than the sea level. They occupy the majority of the islands in the world and change considerably in areas across islands. Sandy islands are always distributed in estuarine areas and are formed by the sediment deposition as a result of the river-sea interaction. Both types of islands possess the island's general characteristics, that is, the isolated space, the unique function, and the distinct vulnerability (Eldridge et al., 2014; Gil et al., 2018; Borges et al., 2018). However, great differences in natural conditions and anthropogenic influences exist between them. On rocky islands, the terrain is ordinarily rugged with eroded hill as the main landform type (Lin et al., 2010; Chi et al., 2018). Correspondingly, many islands are sensitive to geological disasters, such as landslide and collapse (Dai et al., 2001; Gao et al., 2016). The soils are less influenced by the sea intrusion and the terrestrial vegetation is always developed (Chi et al., 2016). For many small islands in middle and high latitudes, the fresh water is scarce due to the low water conservation capacity, which renders the drought a main stress factor for the vegetation-soil system (Koutroulis et al., 2011; Noone et al., 2017). Sandy islands have a generally flat terrain and are susceptible to sea level rise, coastal siltation and erosion, and seawater intrusion (Tian et al., 2010; Chu et al., 2013; Chi et al., 2019b). The seawater influences the soils and results in salinization, which substantially threatens the soil quality and vegetation growth (Aragüés et al., 2014; Scudiero et al., 2017). Wetland vegetation is always observed along the island shore and changes regularly along the salinity gradient (Wang et al., 2007). Human activities also vary considerably between the rocky and sandy islands owing to the differences of natural conditions. Many important ports are developed on rocky islands. For instance, the Yangshan Port, one of the largest ports in the world, is constructed on the rocky islands in the Zhoushan Archipelago; the Jeju Port, an important port in South Korea, is on the Jeju Island; and the Port of Georgetown, one of the best natural deep water harbors on the east coast of Canada, is located on Prince Edward Island (Zhang et al., 2013). The sandy islands are always occupied by a large scale of agricultural activities, including cultivation, plantation, and aquaculture, because of the flat terrain and fertile land (Huang et al., 2008; Qin et al., 2012; Chi et al., 2019b). Besides, urban building and infrastructure constructions are common on both types of islands, however, vary in scales and intensities (Chi et al., 2018, 2019b; Xie et al., 2018). All of the aforementioned conditions contribute to the spatial heterogeneity of the vegetation-soil system between both types of islands and the complex factors influencing the system, and revealing the spatial responses of the vegetation-soil system to the complex factors is highly important for providing reference for island conservation and contributing to the development of island ecology.

Studies on the island vegetation and soil have been extensively conducted. Most of these studies were carried out using the entire island as the analysis unit (Whittaker and Fernández-Palacios, 2007; Weigelt et al., 2013, 2016; Whittaker et al., 2017). The spatial patterns of vegetation and soil at habitat level within the island were also analyzed on different islands (Sfenthourakis and Panitsa, 2012; Chi et al., 2016, 2017, 2019a; Hattermann et al., 2018). However, the existing studies focused only on one type of the rocky and sandy islands, because both types of islands do not always appear in a region, or they are relatively independent of each other. Thus, it failed to reveal the spatial responses of the vegetation-soil system to the complex factors across the two types of islands.

In this study, a sandy-rocky island chain in the Dongtou Archipelago in South China was selected. A total of 10 islands that cover both types are contained in the island chain and connected by bridges, which makes the 10 islands closely interrelated and form a unity in a chain pattern. The coexistence of sandy and rocky islands in a region, the connection of the islands by bridges, and the complex natural and anthropogenic disturbances render the island chain unique in the world and highly suitable for the study on spatial responses of the vegetation-soil system to the complex factors.

Therefore, the sandy-rocky island chain was used as the study area. The vegetation-soil system was represented by using different indicators and three newproposed indices, namely, vegetation health index (VHI), soil health index (SHI), and vegetation-soil system health index (VSSHI). The complex factors were identified in aspects of island basic factors, landscape pattern, terrain condition, and ecological indices. All the data on both types of islands were obtained by

Page $2 / 25$ 
means of field investigation and remote sensing. Then, the spatial responses of the system to the factors were analyzed at two spatial scales, that is, island and site scales, from two perspectives of single factor and complex factors, and using three approaches, including regression analysis, correlation analysis, and canonical correspondence analysis (CCA) ordination (Fig. 1). The study aims to solve the following questions: How the vegetation-soil system spatially varies across the sandy-rocky island chain? How the vegetation-soil system responds to the complex natural and anthropogenic factors at island and site scales? Which factors contributed the most to the spatial pattern of the vegetation-soil system?

\section{Materials And Methods}

\subsection{Study area}

The island chain is located in the southern waters of Zhejiang Province and adjacent to the East China Sea (Fig. 2). It is the core part of the Dongtou Archipelago and belongs to Dongtou District in Wenzhou City. The 10 islands are named as Is. $1-$ Is. 10 along the bridges from the mainland. Is. 1 is a sandy island, and the remaining nine islands are rocky islands. The bridges were initially constructed in the late 1990s. Before the time point, the 10 islands were relatively isolated and the communications among the islands were not frequent. After the year of 2000 , the bridges were continuously constructed and a series of bridges were formed to connect the 10 islands (Fig. 2). Correspondingly, the accessibility from the mainland was greatly improved, the human activities were increasingly intensified, and the communications among the islands were more and more frequent. Is. 1 is the largest island in the archipelago, and Is. 8 is the political, economic, and cultural center of Dongtou District.

The island chain has a homogeneous climate condition because of the small spatial scale, that is, a subtropical, oceanic, and monsoon climate with an average annual temperature and rainfall of $17.9^{\circ} \mathrm{C}$ and $1410.6 \mathrm{~mm}$, respectively (Chi et al., 2019c). The typhoon frequently happens between July and September. However, vegetation, soil, terrain, and human activities are spatially heterogeneous, especially between sandy and rocky islands. The sandy island is constituted by the sediments from the Oujiang River and continuously extends in recent years. It is covered by various wetland vegetation and agricultural crops. Farming, sea reclamation, pond culture, alongshore industry, and housing construction are main types of island use, of which farmland occupied the largest area of the island. The rocky islands have a similar geological background with the neighboring mainland. Forests, most of which are planted protection forests, cover the largest areas of the islands. Urban and port constructions are the main exploitation types. Thus, the vegetation-soil system on the island chain is influenced by complex factors and shows distinct spatial heterogeneity. However, current studies on the vegetation and soil of the island chain are very insufficient.

\subsection{Data source}

\subsubsection{Field investigation and sampling}

We conducted the field investigation and sampling in September 2018. Based on the island area, terrain condition, and plant community, considering the accessibility and representativeness, a total of 111 sampling sites were set (Fig. 2). A size of $20 \times 20 \mathrm{~m}$ was designed for each sampling site, and the species in tree layer were investigated in this size. Two quadrates with a size of $10 \times 10 \mathrm{~m}$ and five quadrates with a size of $1 \times 1 \mathrm{~m}$ were set within the sampling site for the species in shrub and herb layers, respectively. Parameters of abundance, height, coverage, and diameter at breast height of each species in tree layers were measured; and parameters of abundance, height, and coverage of each species in shrub and herb layers were measured. Total coverage in different layers was recorded. Terrain factors, including altitude (Al), slope (SI), and slope aspect (As) were measured. Surface (0-20) soils were sampled using a multipoint mixing method. Soil factors, including bulk density (BD), pH, moisture content (MC), salinity (Sa), total carbon (TC), total nitrogen (TN), organic matter (OM), available phosphorus (AP), and available potassium (AK), were then measured in a laboratory. BD was measured using a cutting ring method; $\mathrm{pH}$ was measured using a potentiometric method; MC was measured using an oven drying method; Sa was measured using a gravimetric method; TC and TN were measured using an elemental analyzer; OM was measured using a potassium dichromate oxidation method; AP was measured using a sodium hydrogen carbonate solution; and AK was measured using ammonium acetate solution and flame photometry.

\subsubsection{Remote sensing}

SPOT 6 and Landsat 8 data in 2017 were adopted. The SPOT 6 data, which has a high spatial resolution, was adopted for generating the island outline (Fig. 2) and landscape types by using a visual interpretation method. The landscape types included 10 types and 24 sub-types, which were shown in a previous study by the authors (Chi et al., 2019c). The Landsat 8 data, which possesses multiple spectra, was used to produce various ecological indices through radiometric calibration, atmospheric correction, and band calculation.

\subsection{Vegetation-soil system}

\subsubsection{Vegetation indicators}

Species composition in tree, shrub, and herb layers were analyzed and the species lists were shown in Tables S1-S3 in the Supplementary Materials. The vegetation was represented by growth condition and plant diversity in the three layers, which comprehensively revealed the quality, vitality, complexity, and stability of the vegetation (Tilman et al., 2006; Chen et al., 2018a). The growth condition was reflected by the total coverage in tree (TCo), shrub (SCo), and herb ( $\mathrm{HCo}$ ) layers. The plant diversity was measured using two frequently-used indices, namely, Shannon-Wiener index ( $\left.\mathrm{H}^{\prime}\right)$ and Pielou index (E), which are obtained based on the important value (IV). The IV is calculated using the following equations:

$$
I V s, i=\left(\frac{A b s, i}{A b s}+\frac{C o s, i}{C o s}+\frac{H e s, i}{H e s}+\frac{D B H s, i}{D B H s}\right) / 3,
$$




$$
I V s, i=\left(\frac{A b s, i}{A b s}+\frac{C o s, i}{\operatorname{Cos}}+\frac{H e s, i}{H e s}\right) / 3
$$

2

where Eq. (1) is used in tree layer, while Eq. (2) is used in shrub and herb layers; $I V_{s, i} A b_{s, i} C o_{s, i} H e_{s, i}$ and $D B H_{s, i}$ are the IV, abundance, coverage, height, and diameter at breast height of species $i$ in sampling site $s$, respectively; and $A b_{s}, \mathrm{Co}_{s}, \mathrm{He}_{s}$, and $D B H_{s}$ are the total abundance, coverage, height, and diameter at breast height in sample site $s$, respectively. The $\mathrm{H}^{\prime}$ and $\mathrm{E}$ was calculated using methods reported by Chi et al. (2019a). Then, the $\mathrm{H}^{\prime}$ in tree (TH'), shrub (SH'), and herb $\left(\mathrm{HH}^{\prime}\right)$ layers, as well as $\mathrm{E}$ in tree (TE), shrub (SE), and herb (HE) layers, were obtained. Therefore, TCo, TH', TE, SCo, SH', SE, HCo, HH', and HE were selected as the indicators of vegetation.

Besides, dominant species were identified based on the IVs. The species possessing the highest 10 IVs were considered the dominant species in the entire study area. For each of sandy and rocky islands, the species possessing the highest five IVs were considered the dominant species.

\subsubsection{Soil indicators}

Nine factors, including BD, pH, MC, Sa, TC, TN, OM, AP, and AK, were used as the soil indicators. BD is a physical parameter that indicates soil porosity and gas; $\mathrm{pH}$ influences soil structure, effectiveness of nutrient elements, microbial activity, and plant growth; MC serves as the main water source for vegetation; Sa represents the soil salinization, which greatly threatens ecosystem health; TC, TN, and OM involve various biogeochemical cycles, of which the latter two, along with AP and AK, are important indicators of soil fertility (Batjes, 1996; Reeves, 1997; Galloway et al., 2008; Cassel et al., 2015).

\subsubsection{Vegetation-soil system}

The VHI, SHI, and VSSHI were proposed to quantify the overall health conditions of the system. To calculate the three indices, each of the 18 indicators was standardized for realizing the comparability of different indicators. The indicators could be divided into positive, negative, and interval ones according to their properties. The higher the value of the positive indicator is, the healthier the system is, which is opposite for the negative indicator. For the interval indicator, the system is healthy when the indicator value is within an interval and tends to be unhealthy when the indicator value deviates from the interval. In this study, the negative indicators include $\mathrm{BD}$ and $\mathrm{Sa}$, the interval indicator refers to $\mathrm{pH}$, and the remaining indicators are positive ones. The standardization method is as follows:

$$
S V i=\left(\begin{array}{cc}
(V i-\text { Vlower }) /(\text { Vupper }- \text { Vlower }) & \text { positive indicator } \\
(\text { Vupper }-V i) /(\text { Vupper }- \text { Vlower }) & \text { negative indicator } \\
(\text { Vupper }- \text { Vlower }) / \mid 2 V i-(\text { Vupper }+ \text { Vlower }) \mid & \text { interval indicator }
\end{array}\right) \text {, }
$$

3

where $S V_{i}$ and $V_{i}$ are the standardized and measured values of an indicator in sampling site $i$, respectively; $V_{\text {lower }}$ and $V_{\text {upper }}$ are the lower and upper limits of the indicator values, respectively. For positive and negative indicators, the $V_{\text {lower }}$ and $V_{\text {upper }}$ denote the $5 \%$ and $95 \%$ percentiles of the indicator values, respectively, to eliminate the effects of extreme values. For interval indicator, that is, $\mathrm{pH}$, the $\mathrm{V}_{\text {lower }}$ and $\mathrm{V}_{\text {upper }}$ are given as 6 and 8 , respectively. Then, the $\mathrm{VHI}$ and $\mathrm{SHI}$ are calculated using the following equations:

$$
\text { VHI or SHI }=\frac{1}{9} \sum S V i \text {, }
$$

4

where $\mathrm{VHI}$ and $\mathrm{SHI}$ are calculated based on the vegetation and soil indicators, respectively. Different indicators indicate different aspects of the system and are all essential to the system. Thus, an equal weight method is adopted. The vegetation and soil indicators are closely interrelated and interacted. Hence, the VSSHI is calculated as follows:

$$
\mathrm{VSSHI}=\sqrt{\mathrm{VHI} \times \mathrm{SHI}}
$$

\section{5}

\subsection{Complex factors}

\subsubsection{Island basic factors}

Island area (IA), shape, proximity to the mainland (PTM), and proportion of sea reclamation area (SRP) are basic factors for the islands, and determine island geomorphology, carrying capacity, biodiversity, and convenience for human exploitation at a macro scale (Wardle et al., 2003; Whittaker and FernándezPalacios, 2007; Weigelt et al., 2016; Chi et al., 2019a). The IA was obtained based on the island outline. The shape was represented using an island shape index (ISI), whose detailed calculation method was shown in Chi et al. (2019a) and a higher ISI indicates a more complex shape. In previous studies on island ecology, the PTM was always measured using the distance to the mainland because the studied islands were not connected with the mainland (Panitsa et al., 2006; Sfenthourakis and Panitsa, 2012; Triantis et al., 2012; Chi et al., 2019a). In this study, the bridges connected the islands with the mainland and different islands in a chain pattern, and the accessibility of island was determined by the order along the bridge from the mainland. Thus, the PTM was represented using the order number. The SRP was obtained by distinguishing the difference of island outlines between the years of 1984 and 2017 , because human exploitations were undeveloped and large scales of sea reclamations were not yet conducted in the 1980s.

\subsubsection{Landscape pattern}


Landscape pattern denotes the composition of different landscape types and the configuration of landscape patches, which influence species number and flow, habitat suitability, soil quality, and many other ecological processes (Thies and Tscharntke, 1999; Zheng et al., 2018; Chi et al., 2018, 2019b). In this study, five common landscape pattern factors, namely, proportion of vegetation area (VP), proportion of construction area (CP), number of patches (NP), areaweighted mean shape index (AWMSI), and landscape isolation index (LII) were used to represent the vegetation coverage, urbanization degree, landscape fragmentation, shape complexity, and patch isolation, respectively. The VP and CP were calculated using the data of landscape types, and the calculation methods for NP, AWMSI, and LII were shown in Chi et al. (2019b). Furthermore, a natural ecosystem damaged index (NEDI) was proposed in a previous study by the authors (Chi et al., 2019c). The NEDI could accurately measure the negative effects of human activities based on the landscape types, sizes, levels, and processes, and was also used as a factor of landscape pattern.

\subsubsection{Terrain condition}

Terrain condition affects local habitat, micro climate, and geological stability, and involves the influences from the sea (Kura et al., 2014; Gao et al., 2016; Ding et al., 2017). Al, SI, As, and distance to the shoreline (DTS) were used to represent the terrain condition. The former three factors were measured in the field investigation. As was processed using a south-direction principle; the processed As ranged from 0 to 1 and a higher As indicates a more southerly direction. The DTS was obtained based on the island outline using the tool of Euclidean Distance in ArcGIS 10.0.

\subsubsection{Ecological indices}

Different types of ecological indices, which represent different characteristics of the island ecosystem, were generated through band calculation based on spectral reflectance. Normalized difference vegetation index (NDVI), salinity index 1 (SI1), salinity index 2 (SI2), brightness temperature (BT), wetness index $(\mathrm{WI})$, and bare soil index (BSI) were adopted, of which NDVI is advantageous for rapidly monitoring the vegetation changes, SI1 and SI2 are effective in representing the soil quality, and $\mathrm{BT}, \mathrm{WI}$, and $\mathrm{BSI}$, which are fundamental physical quantities, represent the heat, humidity, and aridity degrees, respectively. (Douaoui et al., 2006; Allbed et al., 2014; Hu and Xu, 2018).

The aforementioned factors possessed natural and anthropogenic attributes and covered all aspects of potential factors of the vegetation-soil system (Table 1).

Table 1

Complex factors of the vegetation-soil system on the island chain

\begin{tabular}{|c|c|c|}
\hline Aspect & Factors & Scales \\
\hline Island basic factors & IA; ISI; PTM; SRP & Island \\
\hline Landscape pattern & NEDI; VP; CP; NP; AWMSI; LII & Island and site \\
\hline Terrain condition & Al; Sl; As; DTS & Site \\
\hline Ecological indices & NDVI; SI1; SI2; BT; WI; BSI & Site \\
\hline
\end{tabular}

\subsection{Spatial responses to the factors}

\subsubsection{Two spatial scales}

The issue of multiple scales is one of the key issues in the study of island ecology (Sfenthourakis and Panitsa, 2012; Chi et al., 2018, 2019a). The vegetationsoil system spatially varies and responds to the factors at island and site scales (Hattermann et al., 2018; Chi et al., 2019a). At site scale, each sampling site had specific values of vegetation and soil indicators, as well as VHI, SHI, and VSSHI; at island scale, the indicators and indices of an island were calculated using the averages values of the sampling sites within the island. Besides, the influencing factors exert influences at different scales. The island basic factors take effects only at island scale, whereas the terrain condition and ecological indices generate influences only at site scale. The landscape pattern influences the system at the dual spatial scales. At island scale, the landscape pattern was analyzed using the extent of island outline. At site scale, the landscape pattern was analyzed using the extent of surrounding area of each sampling site. The surrounding area was considered as a circle that is determined using the sampling site and a certain length as the center and radius of the circle, respectively. To explore the optimum scale for analyzing the influence of landscape pattern on the vegetation-soil system, the radius was respectively given as $50 \mathrm{~m}, 100 \mathrm{~m}, 150 \mathrm{~m}$, and $200 \mathrm{~m}$, and five of the landscape factors, that is, VP, CP, NP, AWMSI, and LII, were calculated for four times at site scale.

\subsubsection{Two perspectives}

The spatial responses of the vegetation-soil system to the factors were analyzed form perspectives of single factor and complex factors. From the perspective of single factor, the spatial responses to each of the factors were analyzed to reveal the changes of vegetation and soil indicators, VHI, SHI, and VSSHI under the influence of each factor. From the perspective of complex factors, the spatial responses to all of the factors were discussed to clarify the spatial characteristics of the system under the comprehensive influences of the factors and to identify the contributions of different factors to the spatial characteristics.

\subsubsection{Three approaches}

Regression analysis, correlation analysis, and CCA ordination were adopted to reveal the spatial responses at the two spatial scales from the two perspectives. 
Regression analysis was used at island scale from the perspective of single factor. Regression equations of vegetation and soil indicators, $\mathrm{VHI}$, SHI, and VSSHI with each factor were generated through Excel. Four functions, including linear, exponential, logarithmic, and power functions, were attempted, and the one with the highest coefficient of determination $\left(R^{2}\right)$ was selected.

Correlation analysis was used at site scale from the perspective of single factor. Correlation coefficients (CCs) of the indicators and indices with each factor were generated through IBM SPSS 18.

CCA ordination was used at the two spatial scales from the perspective of complex factors. Two types of CCA ordinations were conducted. The first type was aiming to reveal the species spatial pattern influenced by the complex factors. The species IVs in the three layers were successively used as the input data, and the complex factors, as well as the vegetation and soil indicators, were used as the environmental data. In the other type of CCA ordination, the vegetation and soil indicators were considered as the input data, and the complex factors were used as the environmental data to clarify the spatial responses of the vegetation-soil system to the complex factors. The contributions of different factors to the spatial pattern of vegetation-soil system were identified using the canonical eigenvalues (Chi et al., 2016).

\section{Results}

\subsection{Vegetation-soil system}

\subsubsection{Species composition}

The tree, shrub, and herb species summed to 21,71 , and 171 , respectively. In tree layer, the 21 species belonged to 18 genera and 15 families, and Ulmaceae had the most species. In shrub layer, the 71 species belonged to 57 genera and 35 families, of which Rosaceae possessed the highest species number of 10 . In herb layer, the 171 species belonged to 131 genera and 45 families, and Compositae and Gramineae had the highest species numbers of 38 and 29 , respectively.

The dominant species are shown in Tables 2 and 3. In the entire study area, most of the dominant species in tree layer were artificial plantation species; parts of the dominant species in shrub layer, including Citrus reticulata, Pittosporum tobira, and Rhododendron simsii, were artificially planted; and none of the dominant species in herb layer were artificially planted. On different types of islands, Cinnamomum camphora, Casuarina equisetifolia, and Acacia confusa were common dominant species in tree layer on sandy and rocky islands; Pittosporum tobira is the only common dominant species in shrub layer; and the dominant species on sandy and rocky islands were totally different.

Table 2

Dominant species in tree, shrub, and herb layers in the entire study area

\begin{tabular}{|llll|}
\hline Rank & Tree layer & Shrub layer & Herb layer \\
\hline 1 & Casuarina equisetifolia & Boehmeria nivea var. tenacissima & Phragmites australis \\
\hline 2 & Cinnamomum camphora & Citrus reticulata & Spartina alterniflora \\
\hline 3 & Celtis sinensis & Ficus erecta & Aster subulatus \\
\hline 5 & Acacia confusa & Pittosporum tobira & Lygodium japonicum \\
\hline 6 & Melia azedarach & Lespedeza cuneata & Sesbania cannabina \\
\hline 7 & Pinus thunbergii & Schefflera octophylla & Miscanthus floridulus \\
\hline 8 & Acacia mearnsii & Mallotus japonicus & Dicranopteris dichotoma \\
\hline 9 & Sapium sebiferum & Rhus chinensis & Setaria viridis \\
\hline 10 & Ulmus parvifolia & Rhododendron simsii & Echinochloa crusgalli \\
\hline
\end{tabular}


Table 3

Dominant species in tree, shrub, and herb layers on sandy and rocky islands

\begin{tabular}{|c|c|c|c|c|}
\hline Island & Rank & Tree layer & Shrub layer & Herb layer \\
\hline \multirow[t]{5}{*}{ Sandy island } & 1 & Cinnamomum camphora & Citrus reticulata & Phragmites australis \\
\hline & 2 & Metasequoia glyptostroboides & Tamarix chinensis & Spartina alterniflora \\
\hline & 3 & Casuarina equisetifolia & Pittosporum tobira & Sesbania cannabina \\
\hline & 4 & Ficus microcarpa & Vitis vinifera & Aster subulatus \\
\hline & 5 & Acacia confusa & Osmanthus fragrans & Echinochloa crusgalli \\
\hline \multirow[t]{5}{*}{ Rocky island } & 1 & Casuarina equisetifolia & Boehmeria nivea var. tenacissima & Lygodium japonicum \\
\hline & 2 & Celtis sinensis & Ficus erecta & Miscanthus floridulus \\
\hline & 3 & Cinnamomum camphora & Lespedeza cuneata & Dicranopteris dichotoma \\
\hline & 4 & Acacia confusa & Schefflera octophylla & Setaria viridis \\
\hline & 5 & Melia azedarach & Pittosporum tobira & Dianella ensifolia \\
\hline
\end{tabular}

\subsubsection{Vegetation and soil indicators}

The vegetation and soil indicators on different islands are shown in Table 4, and the spatial distributions of the indicators in different sampling sites are shown in Figs. 3 and 4. For the vegetation indicators, the sandy island showed generally lower values of all the indicators except HCo than the rocky islands. At site scale, most of the indicator values did not show clear spatial heterogeneity within the sandy island and exhibited distinct spatial heterogeneity within the rocky islands. For the soil indicators, the sandy island possessed higher BD, pH, MC, Sa, AP, and AK and lower TC, TN, and OM than the rocky islands, and great differences of indicator values existed among different sampling sites in the entire study area.

Table 4

Vegetation and soil indicators on different islands

\begin{tabular}{|c|c|c|c|c|c|c|c|c|c|c|c|}
\hline Item & Is. 1 & Is. 2 & Is. 3 & Is. 4 & Is. 5 & Is. 6 & Is. 7 & Is. 8 & Is. 9 & Is. 10 & Entire area \\
\hline TCo & 6.50 & 39.58 & 70.00 & 10.00 & 20.45 & 70.00 & 51.67 & 38.57 & 65.00 & 45.00 & 23.51 \\
\hline $\mathrm{TH}^{\prime}$ & 0.06 & 0.17 & 0.78 & 1.52 & 0.30 & 0.61 & 0.46 & 0.44 & 0.55 & 0.36 & 0.24 \\
\hline TE & 0.07 & 0.25 & 0.71 & 0.94 & 0.33 & 0.88 & 0.51 & 0.40 & 0.79 & 0.33 & 0.25 \\
\hline SCo & 10.84 & 36.83 & 70.00 & 40.00 & 25.91 & 60.00 & 28.33 & 30.00 & 50.00 & 30.00 & 22.56 \\
\hline $\mathrm{SH}^{\prime}$ & 0.12 & 1.18 & 2.05 & 2.25 & 0.71 & 1.79 & 1.86 & 1.14 & 0.67 & 1.18 & 0.68 \\
\hline SE & 0.10 & 0.63 & 0.99 & 0.98 & 0.42 & 0.92 & 0.94 & 0.73 & 0.97 & 0.91 & 0.42 \\
\hline $\mathrm{HCo}$ & 75.50 & 62.08 & 50.00 & 85.00 & 65.00 & 70.00 & 43.33 & 62.79 & 15.00 & 51.67 & 67.55 \\
\hline $\mathrm{HH}^{\prime}$ & 1.74 & 1.80 & 1.29 & 1.91 & 1.57 & 2.31 & 1.94 & 2.02 & 0.63 & 1.79 & 1.80 \\
\hline HE & 0.83 & 0.93 & 0.93 & 0.83 & 0.85 & 0.96 & 0.95 & 0.93 & 0.91 & 0.94 & 0.87 \\
\hline $\mathrm{BD}$ & 1.30 & 1.10 & 0.89 & 1.31 & 1.22 & 1.13 & 1.00 & 1.17 & 1.07 & 1.01 & 1.21 \\
\hline $\mathrm{pH}$ & 7.85 & 5.59 & 4.99 & 5.17 & 6.79 & 5.54 & 5.95 & 5.98 & 4.31 & 4.90 & 6.79 \\
\hline MC & 0.28 & 0.31 & 0.25 & 0.22 & 0.27 & 0.26 & 0.25 & 0.21 & 0.09 & 0.17 & 0.26 \\
\hline Sa & 1.68 & 1.50 & 0.30 & 0.01 & 2.34 & 0.01 & 0.38 & 0.16 & 0.83 & 0.11 & 1.22 \\
\hline $\mathrm{TC}$ & 11.38 & 14.60 & 34.19 & 15.89 & 15.22 & 23.18 & 71.89 & 20.26 & 63.15 & 31.88 & 17.36 \\
\hline $\mathrm{TN}$ & 0.55 & 1.13 & 2.60 & 0.71 & 0.90 & 1.49 & 3.23 & 1.36 & 3.71 & 2.34 & 1.03 \\
\hline OM & 12.25 & 18.46 & 22.22 & 9.81 & 17.25 & 25.65 & 39.58 & 22.82 & 45.10 & 31.99 & 17.84 \\
\hline AP & 21.47 & 14.39 & 13.94 & 8.65 & 13.50 & 74.88 & 17.21 & 19.64 & 24.04 & 13.53 & 19.44 \\
\hline AK & 370.19 & 190.03 & 153.23 & 87.66 & 311.37 & 158.23 & 255.89 & 172.04 & 235.29 & 167.17 & 278.70 \\
\hline
\end{tabular}

TCo: total coverage in tree layer; TH': Shannon-Wiener index in tree layer; TE: Pielou index in tree layer; SCo: total coverage in shrub layer; SH': ShannonWiener index in shrub layer; SE: Pielou index in shrub layer; HCo: total coverage in herb layer; HH': Shannon-Wiener index in herb layer; HE: Pielou index in herb layer; BD: bulk density; MC: moisture content; Sa: salinity; TC: total carbon; TN: total nitrogen; OM: organic matter; AP: available phosphorus; AK: available potassium. The unit for TCo, SCo, $\mathrm{HCo}$, and $\mathrm{MC}$ is \%; the unit for $\mathrm{BD}$ is $\mathrm{g} / \mathrm{cm}^{3}$; the unit for $\mathrm{Sa}, \mathrm{TC}, \mathrm{TN}$, and $\mathrm{OM}$ is $\mathrm{g} / \mathrm{kg}$; the unit for $\mathrm{AP}$ and $\mathrm{AK}$ is $\mathrm{mg} / \mathrm{kg}$; and the remaining factors are dimensionless. 


\subsubsection{VHI, SHI, and VSSHI}

The spatial distributions of the three indices among different islands and different sampling sites are shown in Figs. 5 and 6 . Of all the islands, the sandy island possessed the lowest VHI and VSSHI, as well as the second lowest SHI. In the rocky islands, Is. 4 and Is. 7 showed the lowest and highest SHIs, respectively, and Is. 6 exhibited the highest VHI and VSSHI (Fig. 5). At site scale, the VHI showed distinct spatial heterogeneity among different sampling sites, whereas the SHI was not as heterogeneous as the VHI. The spatial distribution of VSSHI combined the characteristics of VHI and SHI. In addition, the spatial heterogeneity within the sandy island was lower than that within the rocky islands (Fig. 6).

\subsection{Spatial responses to single factor}

\subsubsection{Island scale}

The regression equations of the factors with each indicator and index at island scale are shown in Table 5. The response was considered as insensitive, sensitive, and very sensitive when $\mathrm{R}^{2}$ was $<0.3, \geq 0.3$ and $<0.6$, and $\geq 0.6$, respectively. The equation trends were classified as increasing and decreasing trends, which indicated that the dependent variable monotonically increased and decreased with the increase in the independent variable, respectively. The vegetation-soil system sensitively responded to most of the factors at island scale. For the 18 vegetation and soil indicators, six and five indicators had very sensitive and sensitive responses, respectively, to IA; only two indicators showed sensitive responses to ISI; one and nine indicators exhibited very sensitive and sensitive responses, respectively, to PTM; nine and seven indicators possessed very sensitive and sensitive responses, respectively, to SRP; three and eight indicators showed very sensitive and sensitive responses, respectively, to NEDI; seven and two indicators had very sensitive and sensitive responses, respectively, to VP; only three indicators exhibited sensitive responses to $\mathrm{CP}$; three and six indicators showed very sensitive and sensitive responses, respectively, to NP; two and six indicators had very sensitive and sensitive responses, respectively, to AWMSl; and three and four indicators exhibited very sensitive and sensitive responses, respectively, to LII. 
Table 5

(a) Regression equations of factors with each indicator and index at island scale

\begin{tabular}{|c|c|c|c|c|c|c|c|c|c|c|c|c|c|c|c|}
\hline \multirow[t]{2}{*}{ Items } & \multicolumn{3}{|l|}{ IA } & \multicolumn{3}{|l|}{ ISI } & \multicolumn{3}{|l|}{ PTM } & \multicolumn{3}{|l|}{ SRP } & \multicolumn{3}{|l|}{ NEDI } \\
\hline & Type & $\mathrm{R}^{2}$ & Trend & Type & $\mathrm{R}^{2}$ & Trend & Type & $\mathbf{R}^{2}$ & Trend & Type & $\mathrm{R}^{2}$ & Trend & Type & $\mathrm{R}^{2}$ & Trend \\
\hline TCo & $b$ & 0.37 & $D$ & $\mathrm{~d}$ & 0.24 & 1 & $\mathrm{~d}$ & 0.36 & 1 & $b$ & 0.45 & $\mathrm{D}$ & $b$ & 0.24 & $\mathrm{D}$ \\
\hline $\mathrm{TH}^{\prime}$ & $\mathrm{d}$ & 0.69 & $D$ & $c$ & 0.22 & $D$ & $\mathrm{~d}$ & 0.35 & 1 & $b$ & 0.50 & $\mathrm{D}$ & $b$ & 0.49 & $\mathrm{D}$ \\
\hline TE & $c$ & 0.82 & $D$ & $c$ & 0.21 & $D$ & $\mathrm{~d}$ & 0.41 & 1 & $b$ & 0.58 & $D$ & $b$ & 0.57 & $\mathrm{D}$ \\
\hline SCo & $c$ & 0.67 & $D$ & $a$ & 0.02 & $D$ & $\mathrm{~d}$ & 0.19 & 1 & $b$ & 0.54 & $\mathrm{D}$ & $b$ & 0.42 & $\mathrm{D}$ \\
\hline $\mathrm{SH}^{\prime}$ & $b$ & 0.65 & $D$ & $b$ & 0.06 & 1 & $\mathrm{~d}$ & 0.28 & 1 & $b$ & 0.63 & D & $b$ & 0.33 & $\mathrm{D}$ \\
\hline SE & $b$ & 0.75 & $D$ & $\mathrm{~b}$ & 0.07 & 1 & $\mathrm{~d}$ & 0.54 & 1 & $a$ & 0.89 & $\mathrm{D}$ & $\mathrm{a}$ & 0.65 & $\mathrm{D}$ \\
\hline HCo & a & 0.14 & 1 & c & 0.18 & D & $\mathrm{a}$ & 0.32 & D & d & 0.57 & 1 & $d$ & 0.30 & I \\
\hline $\mathrm{HH}^{\prime}$ & $d$ & 0.08 & 1 & $b$ & 0.01 & 1 & $b$ & 0.05 & D & $d$ & 0.26 & I & $d$ & 0.18 & I \\
\hline HE & a & 0.20 & $\mathrm{D}$ & $b$ & 0.33 & 1 & $\mathrm{~d}$ & 0.26 & 1 & $b$ & 0.46 & $\mathrm{D}$ & $b$ & 0.15 & $\mathrm{D}$ \\
\hline BD & a & 0.28 & I & c & 0.38 & D & c & 0.13 & D & $a$ & 0.30 & I & a & 0.06 & I \\
\hline $\mathrm{pH}$ & a & 0.65 & I & $c$ & 0.01 & $D$ & $c$ & 0.36 & $D$ & $a$ & 0.79 & I & $\mathrm{a}$ & 0.75 & I \\
\hline $\mathrm{MC}$ & $c$ & 0.12 & 1 & $b$ & 0.00 & 1 & a & 0.60 & $D$ & $d$ & 0.61 & I & c & 0.67 & 1 \\
\hline $\mathrm{Sa}$ & $\mathrm{d}$ & 0.36 & I & $\mathrm{d}$ & 0.19 & I & $c$ & 0.25 & $\mathrm{D}$ & $\mathrm{a}$ & 0.61 & I & a & 0.38 & I \\
\hline TC & $b$ & 0.35 & $D$ & $\mathrm{~d}$ & 0.13 & I & $\mathrm{d}$ & 0.41 & 1 & $d$ & 0.65 & $D$ & $b$ & 0.23 & $\mathrm{D}$ \\
\hline $\mathrm{TN}$ & $b$ & 0.37 & D & $d$ & 0.25 & 1 & $\mathrm{~d}$ & 0.43 & 1 & c & 0.63 & D & $\mathrm{b}$ & 0.26 & D \\
\hline $\mathrm{OM}$ & $\mathrm{a}$ & 0.20 & $D$ & $d$ & 0.26 & I & $\mathrm{a}$ & 0.56 & I & c & 0.65 & D & c & 0.30 & D \\
\hline AP & $c$ & 0.03 & $D$ & $c$ & 0.16 & $D$ & $b$ & 0.02 & 1 & $a$ & 0.02 & $\mathrm{D}$ & a & 0.06 & $\mathrm{D}$ \\
\hline AK & $d$ & 0.42 & I & $d$ & 0.04 & 1 & c & 0.14 & $D$ & $a$ & 0.60 & I & a & 0.44 & I \\
\hline VHI & c & 0.69 & $D$ & c & 0.02 & $\mathrm{D}$ & $d$ & 0.27 & I & $b$ & 0.68 & D & $b$ & 0.44 & $\mathrm{D}$ \\
\hline SHI & $\mathrm{a}$ & 0.19 & $D$ & $d$ & 0.14 & 1 & $\mathrm{a}$ & 0.25 & I & $c$ & 0.36 & D & c & 0.10 & D \\
\hline VSSHI & $b$ & 0.63 & $\mathrm{D}$ & $b$ & 0.02 & 1 & $\mathrm{~d}$ & 0.35 & 1 & $b$ & 0.68 & $\mathrm{D}$ & $b$ & 0.38 & $\mathrm{D}$ \\
\hline
\end{tabular}


Table 5

(b) Regression equations of factors with each indicator and index at island scale

\begin{tabular}{|c|c|c|c|c|c|c|c|c|c|c|c|c|c|c|c|}
\hline \multirow[t]{2}{*}{ Items } & \multicolumn{3}{|l|}{ VP } & \multicolumn{3}{|l|}{$\mathrm{CP}$} & \multicolumn{3}{|l|}{ NP } & \multicolumn{3}{|c|}{ AWMSI } & \multicolumn{3}{|l|}{ LII } \\
\hline & Type & $\mathrm{R}^{2}$ & Trend & Type & $\mathrm{R}^{2}$ & Trend & Type & $\mathrm{R}^{2}$ & Trend & Type & $\mathrm{R}^{2}$ & Trend & Type & $\mathrm{R}^{2}$ & Trend \\
\hline TCo & $\mathrm{d}$ & 0.37 & I & a & 0.01 & $\mathrm{D}$ & a & 0.21 & $\mathrm{D}$ & a & 0.18 & D & a & 0.20 & I \\
\hline $\mathrm{TH}^{\prime}$ & $\mathrm{d}$ & 0.75 & I & c & 0.41 & $\mathrm{D}$ & d & 0.64 & $\mathrm{D}$ & $d$ & 0.63 & D & b & 0.04 & 1 \\
\hline TE & $d$ & 0.83 & I & c & 0.50 & $\mathrm{D}$ & c & 0.82 & D & c & 0.83 & D & b & 0.14 & 1 \\
\hline SCo & $d$ & 0.76 & I & b & 0.21 & $\mathrm{D}$ & c & 0.63 & $\mathrm{D}$ & $d$ & 0.50 & D & b & 0.08 & 1 \\
\hline $\mathrm{SH}^{\prime}$ & $d$ & 0.75 & 1 & $b$ & 0.04 & D & c & 0.46 & D & c & 0.40 & D & a & 0.02 & D \\
\hline SE & $d$ & 0.91 & I & c & 0.19 & D & c & 0.51 & $\mathrm{D}$ & a & 0.44 & D & a & 0.18 & 1 \\
\hline HCo & d & 0.08 & D & d & 0.17 & 1 & $b$ & 0.09 & I & $b$ & 0.07 & I & $b$ & 0.77 & D \\
\hline $\mathrm{HH}^{\prime}$ & $b$ & 0.02 & D & $d$ & 0.29 & I & $b$ & 0.07 & I & $b$ & 0.08 & I & $b$ & 0.48 & $\mathrm{D}$ \\
\hline HE & $\mathrm{d}$ & 0.25 & I & c & 0.07 & I & a & 0.05 & D & a & 0.02 & D & $d$ & 0.09 & I \\
\hline$B D$ & $c$ & 0.16 & D & c & 0.04 & D & $b$ & 0.18 & I & b & 0.09 & I & a & 0.04 & $D$ \\
\hline $\mathrm{pH}$ & c & 0.84 & D & $d$ & 0.38 & I & $c$ & 0.42 & 1 & a & 0.39 & I & $b$ & 0.36 & D \\
\hline MC & a & 0.23 & D & $d$ & 0.47 & I & $c$ & 0.08 & I & c & 0.09 & 1 & b & 0.74 & $D$ \\
\hline Sa & b & 0.52 & D & b & 0.20 & 1 & $d$ & 0.33 & I & $d$ & 0.38 & I & c & 0.04 & D \\
\hline $\mathrm{TC}$ & d & 0.22 & I & $d$ & 0.04 & D & $b$ & 0.23 & D & $b$ & 0.18 & D & a & 0.49 & 1 \\
\hline TN & d & 0.28 & I & c & 0.04 & D & $b$ & 0.22 & D & a & 0.15 & D & a & 0.49 & I \\
\hline OM & $c$ & 0.14 & I & c & 0.03 & D & a & 0.11 & $D$ & a & 0.07 & D & a & 0.65 & 1 \\
\hline AP & a & 0.04 & I & a & 0.02 & D & $c$ & 0.06 & D & $c$ & 0.08 & D & $d$ & 0.10 & I \\
\hline AK & $\mathrm{a}$ & 0.74 & D & b & 0.19 & I & $d$ & 0.35 & I & $d$ & 0.34 & I & $b$ & 0.01 & I \\
\hline VHI & $d$ & 0.81 & I & a & 0.13 & D & $c$ & 0.63 & D & $c$ & 0.57 & D & $d$ & 0.02 & I \\
\hline SHI & c & 0.09 & 1 & $d$ & 0.01 & I & a & 0.14 & D & a & 0.10 & D & a & 0.29 & I \\
\hline VSSHI & d & 0.62 & I & b & 0.06 & D & c & 0.46 & D & b & 0.41 & D & b & 0.12 & 1 \\
\hline
\end{tabular}

The VHI and VSSHI sensitively or very sensitively responded to IA, SRP, NEDI, VP, NP, and AWMSI, and equations showed decreasing trends except those for VP. The SHI sensitively responded only to SRP, and the equation showed a decreasing trend.

\subsubsection{Site scale}

CCs of factors with each indicator and index at site scale are shown in Table 6 . We considered the response as insensitive, sensitive, and very sensitive when the $P$ value $\geq 0.05,<0.05$ and $\geq 0.01$, and $<0.01$, respectively. For the vegetation and soil indicators, 10 and two indicators very sensitively and sensitively responded to $\mathrm{Al}$, respectively; 12 and two indicators very sensitively and sensitively responded to SI, respectively; one and two indicators very sensitively and sensitively responded to As, respectively; three and two indicators very sensitively and sensitively responded to DTS, respectively; 13 and two indicators very sensitively and sensitively responded to NDVI, respectively; 14 indicators very sensitively responded to SI1; five and five indicators very sensitively and sensitively responded to SI2, respectively; 12 and one indicators very sensitively and sensitively responded to BT, respectively; 11 and four indicators very sensitively and sensitively responded to WI, respectively; 14 indicators very sensitively responded to BSl; and 11 and two indicators very sensitively and sensitively responded to NEDI, respectively. The CCs for VP, CP, NP, AWMSI, and LII changed across the 50m, $100 \mathrm{~m}, 150 \mathrm{~m}$, and $200 \mathrm{~m}$ scales, and the scale that possessed the most very sensitive and sensitive indicators was selected to conducted the next analysis from the perspective of complex factors. That is, LII at $100 \mathrm{~m}$ scale, NP at $150 \mathrm{~m}$ scale, and VP, CP, and AWMSI at $200 \mathrm{~m}$ scale were selected. 11 and two indicators possessed very sensitive and sensitive responses, respectively, to VP; four and five indicators showed very sensitive and sensitive responses, respectively, to CP; four and three indicators exhibited very sensitive and sensitive responses, respectively, to NP; eight and four indicators showed very sensitive and sensitive responses, respectively, to AWMSI; and one and two indicators had very sensitive and sensitive responses, respectively, to LII. 
Table 6

(a) Correlation coefficients of factors with each indicator and index at site scale

\begin{tabular}{|c|c|c|c|c|c|c|c|c|c|c|}
\hline Items & $\mathrm{Al}$ & SI & As & DTS & NDVI & SI1 & $\mathrm{SI} 2$ & BT & WI & BSI \\
\hline TCo & $.482^{* *}$ & $.434^{\star \star}$ & -.092 & -.132 & $.659^{\star \star}$ & $-.680^{* \star}$ & $-.273^{\star \star}$ & $-.485^{\star \star}$ & $.572^{\star \star}$ & $-.740^{\star *}$ \\
\hline $\mathrm{TH}^{\prime}$ & $.405^{\star *}$ & $.289^{\star \star}$ & -.028 & -.092 & $.499^{\star *}$ & $-.509^{\star *}$ & $-.205^{\star}$ & $-.437^{\star \star}$ & $.418^{\star *}$ & $-.554^{\star *}$ \\
\hline TE & $.384^{\star *}$ & $.356^{\star *}$ & -.017 & -.121 & $.525^{\star *}$ & $-.529^{\star \star}$ & $-.197^{\star}$ & $-.419^{\star *}$ & $.417^{* *}$ & $-.563^{\star \star}$ \\
\hline SCo & $.425^{\star *}$ & $.376^{\star \star}$ & -.141 & -.030 & $.584^{\star *}$ & $-.552^{\star \star}$ & -.099 & $-.495^{\star *}$ & $.377^{\star \star}$ & $-.555^{\star *}$ \\
\hline $\mathrm{SH}^{\prime}$ & $.634^{\star *}$ & $.394^{\star \star}$ & $-.223^{\star}$ & $-.212^{\star}$ & $.577^{\star \star}$ & $-.636^{\star \star}$ & $-.319^{\star \star}$ & $-.579^{\star \star}$ & $.419^{\star *}$ & $-.605^{\star *}$ \\
\hline SE & $.566^{\star *}$ & $.437^{\star *}$ & $-.259^{\star \star}$ & $-.270^{\star \star}$ & $.513^{\star \star}$ & $-.567^{\star \star}$ & $-.278^{\star *}$ & $-.554^{\star \star}$ & $.381^{\star *}$ & $-.530^{\star *}$ \\
\hline HCo & -.128 & $-.353^{\star \star}$ & .027 & .083 & $-.331^{\star *}$ & $.324^{\star *}$ & .093 & $.288^{\star *}$ & $-.344^{\star *}$ & $.419^{\star *}$ \\
\hline $\mathrm{HH}^{\prime}$ & .037 & $-.242^{\star}$ & .168 & .098 & .073 & .096 & $.239^{*}$ & .136 & $-.206^{\star}$ & .070 \\
\hline $\mathrm{HE}$ & .104 & .025 & .065 & .153 & $.206^{*}$ & -.093 & .104 & .061 & -.066 & -.109 \\
\hline$B D$ & $-.324^{\star *}$ & $-.288^{\star *}$ & .084 & $.279^{\star \star}$ & $-.231^{\star}$ & $.346^{\star *}$ & $.324^{\star *}$ & $.426^{\star *}$ & $-.272^{\star *}$ & $.312^{\star *}$ \\
\hline $\mathrm{pH}$ & $-.579^{\star \star}$ & $-.453^{\star \star}$ & $.200^{*}$ & .144 & $-.658^{\star \star}$ & $.644^{\star \star}$ & $.192^{\star}$ & $.497^{\star \star}$ & $-.424^{\star \star}$ & $.640^{\star *}$ \\
\hline MC & -.108 & -.180 & .015 & .064 & -.123 & .048 & -.061 & .000 & -.018 & .080 \\
\hline Sa & $-.264^{\star \star}$ & -.145 & .062 & -.123 & $-.351^{\star \star}$ & $.306^{\star *}$ & .053 & .138 & $-.189^{\star}$ & $.311^{\star *}$ \\
\hline $\mathrm{TC}$ & .167 & $.472^{\star \star}$ & -.101 & $-.212^{\star}$ & $.332^{\star \star}$ & $-.416^{\star *}$ & $-.327^{\star *}$ & $-.329^{\star \star}$ & $.309^{\star *}$ & $-.403^{* \star}$ \\
\hline $\mathrm{TN}$ & $.199^{*}$ & $.464^{\star *}$ & -.083 & $-.248^{\star \star}$ & $.371^{\star *}$ & $-.417^{\star \star}$ & $-.240^{\star}$ & $-.398^{\star \star}$ & $.317^{\star \star}$ & $-.422^{* *}$ \\
\hline $\mathrm{OM}$ & .153 & $.351^{\star *}$ & .023 & -.186 & $.355^{\star \star}$ & $-.318^{\star *}$ & -.099 & $-.195^{\star}$ & $.240^{\star}$ & $-.356^{\star *}$ \\
\hline AP & $-.212^{\star}$ & -.103 & .167 & .086 & -.040 & .084 & .112 & .060 & -.009 & .057 \\
\hline AK & $-.411^{\star \star}$ & $-.230^{*}$ & .064 & .144 & $-.370^{\star *}$ & $.327^{\star \star}$ & .049 & $.293^{\star *}$ & $-.197^{\star}$ & $.337^{\star \star}$ \\
\hline VHI & $.571^{\star *}$ & $.372^{\star *}$ & -.118 & -.141 & $.654^{\star *}$ & $-.645^{\star *}$ & $-.219^{\star}$ & $-.528^{\star *}$ & $.437^{\star \star}$ & $-.652^{\star *}$ \\
\hline SHI & .045 & $.261^{\star *}$ & -.001 & -.144 & $.268^{\star \star}$ & $-.302^{\star \star}$ & -.182 & $-.260^{\star *}$ & $.235^{\star}$ & $-.296^{\star *}$ \\
\hline VSSHI & $.495^{\star *}$ & $.433^{\star \star}$ & -.095 & -.162 & $.662^{\star \star}$ & $-.662^{* \star}$ & $-.249^{\star \star}$ & $-.521^{\star \star}$ & $.442^{* *}$ & $-.660^{\star *}$ \\
\hline
\end{tabular}


Table 6

(b) Correlation coefficients of factors with each indicator and index at site scale

\begin{tabular}{|c|c|c|c|c|c|c|c|c|c|c|c|c|c|c|}
\hline \multirow[t]{2}{*}{ Items } & \multirow[t]{2}{*}{ NEDI } & \multicolumn{5}{|l|}{$50 \mathrm{~m}$} & \multicolumn{5}{|l|}{$100 \mathrm{~m}$} & \multicolumn{3}{|l|}{$150 \mathrm{~m}$} \\
\hline & & VP & $\mathrm{CP}$ & NP & AWMSI & LII & VP & $\mathrm{CP}$ & NP & AWMSI & LII & VP & $\mathrm{CP}$ & NP \\
\hline TCo & $-.544^{\star *}$ & $.461^{* *}$ & $-.355^{\star *}$ & .114 & .136 & $.226^{*}$ & $.482^{\star *}$ & $-.291^{\star *}$ & $.215^{\star}$ & $.279^{\star \star}$ & -.004 & $.500^{\star *}$ & $-.290^{\star *}$ & $.230^{*}$ \\
\hline $\mathrm{TH}^{\prime}$ & $-.455^{\star *}$ & $.393^{\star \star}$ & $-.254^{\star \star}$ & $.242^{\star}$ & $.245^{\star *}$ & .166 & $.432^{\star *}$ & $-.249^{\star *}$ & .175 & $.236^{*}$ & -.027 & $.456^{\star *}$ & $-.259^{\star \star}$ & .134 \\
\hline TE & $-.462^{\star \star}$ & $.417^{\star \star}$ & $-.265^{\star \star}$ & $.248^{\star \star}$ & $.196^{*}$ & .169 & $.439^{\star *}$ & $-.236^{\star}$ & $.200^{*}$ & $.241^{*}$ & -.024 & $.452^{* *}$ & $-.228^{\star}$ & .167 \\
\hline SCo & $-.372^{\star *}$ & $.221^{\star}$ & $-.296^{\star \star}$ & .147 & $.209^{\star}$ & .037 & $.271^{\star *}$ & $-.277^{\star *}$ & .181 & $.260^{\star *}$ & -.033 & $.304^{\star \star}$ & $-.259^{\star \star}$ & $.217^{\star}$ \\
\hline $\mathrm{SH}^{\prime}$ & $-.589^{\star *}$ & $.497^{\star \star}$ & $-.269^{\star \star}$ & .139 & $.274^{\star \star}$ & .127 & $.555^{\star *}$ & $-.286^{\star *}$ & .164 & $.275^{\star *}$ & -.029 & $.588^{\star \star}$ & $-.293^{\star \star}$ & .164 \\
\hline SE & $-.530^{\star *}$ & $.415^{\star \star}$ & $-.204^{\star}$ & .150 & $.255^{\star *}$ & .131 & $.474^{\star *}$ & $-.222^{\star}$ & .179 & $.303^{\star *}$ & -.055 & $.512^{\star \star}$ & $-.234^{*}$ & .176 \\
\hline HCo & .156 & -.061 & $.199^{\star}$ & -.011 & -.001 & -.179 & -.074 & .179 & -.110 & -.097 & .039 & -.095 & .163 & $-.188^{\prime}$ \\
\hline $\mathrm{HH}^{\prime}$ & $.232^{*}$ & $-.213^{\star}$ & $.228^{\star}$ & .014 & .039 & -.053 & $-.201^{*}$ & $.210^{\star}$ & .001 & -.007 & -.088 & $-.190^{\star}$ & .182 & -.040 \\
\hline $\mathrm{HE}$ & .097 & -.068 & .059 & -.042 & -.082 & .059 & -.075 & .060 & .024 & -.021 & $-.202^{*}$ & -.085 & .063 & .033 \\
\hline $\mathrm{BD}$ & $.410^{\star \star}$ & $-.286^{\star *}$ & .163 & -.086 & $-.269^{\star \star}$ & -.161 & $-.381^{\star *}$ & .183 & -.151 & $-.254^{\star \star}$ & $-.221^{*}$ & $-.429^{\star *}$ & .178 & -.120 \\
\hline $\mathrm{pH}$ & $.410^{\star *}$ & $-.232^{\star}$ & .169 & $-.206^{*}$ & $-.277^{\star \star}$ & $-.199^{*}$ & $-.306^{\star \star}$ & .183 & $-.281^{\star \star}$ & $-.379^{\star \star}$ & .001 & $-.359^{\star \star}$ & $.194^{\star}$ & $-.329^{\prime}$ \\
\hline MC & .022 & -.038 & -.058 & -.039 & -.053 & -.125 & -.059 & -.022 & -.051 & -.068 & -.036 & -.073 & .013 & -.130 \\
\hline Sa & .023 & .073 & -.041 & -.093 & -.087 & -.057 & .057 & -.049 & -.144 & -.143 & -.047 & .039 & -.025 & -.174 \\
\hline $\mathrm{TC}$ & $-.282^{\star \star}$ & $.211^{\star}$ & -.088 & .066 & .130 & .060 & $.254^{\star *}$ & -.089 & $.227^{*}$ & $.244^{\star *}$ & .008 & $.294^{\star *}$ & -.102 & $.259^{\star *}$ \\
\hline $\mathrm{TN}$ & $-.265^{\star *}$ & .095 & -.061 & .067 & .183 & .063 & .179 & -.090 & $.236^{\star}$ & $.304^{\star \star}$ & -.030 & $.229^{\star}$ & -.101 & $.305^{\star *}$ \\
\hline $\mathrm{OM}$ & -.157 & .034 & .062 & .061 & .138 & .076 & .116 & -.011 & .181 & $.251^{\star *}$ & -.026 & .161 & .000 & $.247^{\star \star}$ \\
\hline AP & $.309^{\star \star}$ & $-.415^{\star \star}$ & $.244^{\star \star}$ & .056 & .109 & -.119 & $-.370^{\star *}$ & $.247^{\star \star}$ & .038 & .092 & $.362^{\star \star}$ & $-.337^{\star \star}$ & $.240^{\star}$ & .002 \\
\hline AK & $.193^{\star}$ & -.094 & .054 & -.116 & -.172 & -.077 & -.148 & .065 & -.064 & -.169 & -.036 & -.174 & .092 & -.115 \\
\hline VHI & $-.521^{\star *}$ & $.426^{* *}$ & $-.250^{\star \star}$ & $.212^{\star}$ & $.261^{\star *}$ & .152 & $.479^{\star *}$ & $-.240^{\star}$ & $.225^{\star}$ & $.312^{\star \star}$ & -.056 & $.511^{\star *}$ & $-.248^{\star \star}$ & $.199^{\star}$ \\
\hline $\mathrm{SHI}$ & -.088 & -.098 & .045 & .090 & $.219^{\star}$ & -.019 & -.005 & .017 & $.227^{\star}$ & $.268^{\star *}$ & .080 & .050 & .028 & $.226^{\star}$ \\
\hline VSSHI & $-.456^{* *}$ & $.315^{\star *}$ & -.186 & $.199^{\star}$ & $.289^{\star *}$ & .104 & $.391^{* *}$ & -.181 & $.277^{\star *}$ & $.358^{\star *}$ & -.031 & $.438^{\star *}$ & -.182 & $.267^{\star *}$ \\
\hline
\end{tabular}

All of the VHI, SHI, and VSSHI very sensitively or sensitively responded to SI, NDVI, SI1, BT, WI, BSI, NP, and AWMSI. The VHI and VSSHI very sensitively or sensitively responded to $\mathrm{Al}, \mathrm{SI}$, NEDI, and VP. Only VHI sensitively responded to CP. None of the three indices very sensitively or sensitively responded to As, DTS, and LII.

\subsection{Spatial responses to complex factors}

\subsubsection{Spatial responses of species}

The CCA ordination diagrams of species with environmental variables are shown in Figs. 7 and 8 . The environmental variables included the complex factors, as well as the vegetation and soil indicators. The spatial position of the species relative to the environmental variable denoted their relationship, and the length of the environmental variable indicated its influence.

At island scale, in tree layer, TCo, TH', TE, SCo, SH', SE, HE, TN, OM, ISI, PTM, and VP distinctly increased and HCo, IA, SRP, NEDI, BD, pH, MC, Sa, and AK distinctly decreased from left to right along Axis $1 ; \mathrm{HH}$ and $\mathrm{BD}$ distinctly decreased from bottom to top along Axis 2 . All species were distributed over the diagram, yet the dominant species except species 4 and 8 were close to each other. In shrub layer, HCo, BD, pH, AK, IA, SRP, and NEDI distinctly increased and OM, TCo, TH', TE, SCo, SH', SE, HE, ISI, PTM, and VP distinctly decreased from left to right along Axis 1; TC, TN, OM, and LII distinctly increased and HCo, HH', and $\mathrm{CP}$ distinctly decreased from bottom to top along Axis 2. All species and dominant species were around the origin in a concentrated distribution. In herb layer, TCo, TH', TE, SCo, SH', SE, HE, OM, TC, TN, ISI, PTM, VP, and LII distinctly increased and HCo, BD, pH, MC, Sa, AK, IA, SRP, and NEDI distinctly decreased from left to right along Axis 1; TC distinctly increased and $\mathrm{HH}^{\prime}$ distinctly decreased from bottom to top along Axis 2 . Most of the species were distributed around the origin, including all of the dominant species. Still, a small part of species were scattered in the edge of the diagram.

At site scale, in tree layer, $\mathrm{HCo}, \mathrm{HH}^{\prime}$, Sa, and AK distinctly increased and DTS distinctly decreased from left to right along Axis 1; BD, pH, Sa, and SI2 distinctly increased and SE, TC, TN, and VP distinctly decreased from bottom to top along Axis 2. All species were highly concentrated near the origin. In shrub layer, pH, $\mathrm{MC}, \mathrm{Sa}$, and AK distinctly increased from left to right along Axis 1; BD, pH, DTS, SI1, BT, and NEDI distinctly increased and TCo, SH', SE, Al, and VP distinctly 
decreased from bottom to top along Axis 2 . Shrub species were also distributed in a concentrated spatial pattern, yet to a lesser degree than tree species. In herb layer, TCo, TH', SCo, SH', SE, OM, TN, Al, SI, WI, NDVI, and VP distinctly increased and HCo, pH, Sa, AK, SI1, BT, BSI, and NEDI distinctly decreased from left to right along Axis 1; Sa and VP distinctly increased and HH', HE, BD, BT, and NEDI distinctly decreased from bottom to top along Axis 2 . The species were dispersedly distributed in the diagram. In the dominant species, species $1,3,5,8$, 9, and 10 were located closely in the third quadrant, species 4,6 , and 7 were located closely in the first quadrant, and species 2 was in the edge of the diagram and far from the other dominant species.

\subsubsection{Spatial responses of vegetation and soil indictors}

The CCA ordination diagrams of vegetation and soil indicators with the complex factors are shown in Fig. 9. At island scale, IA, SRP, NEDI, NP, and AWMSI distinctly increased and PTM and VP distinctly decreased from left to right along Axis 1; PTM and LII distinctly decreased from bottom to top along Axis 2 . TCo, TN, TC, and OM were generally high on islands with high PTM, VP, and LII and low IA, SRP, NEDI, NP, and AWMSI. Sa was high on islands with high IA, SRP, NEDI, NP, and AWMSI and low PTM, VP, and LII, whereas TH', TE, SCo, SH', SE, and AP showed the opposite spatial responses, and HCo also exhibited the inclination on islands with low PTM and LII. The remaining indicators, including HH', $\mathrm{HE}, \mathrm{BD}, \mathrm{pH}, \mathrm{MC}$, and AK, were generally distributed around the origin. At site scale, AI, SI, NDVI, WI, AWMSI, and VP distinctly increased and SI1, BT, BSI, and NEDI distinctly decreased from left to right along Axis 1; NEDI and LII distinctly increased and VP distinctly decreased from bottom to top along Axis 2 . High TCo, TH', TE, SCo, SH', SE, TC, TN, and OM and low Sa were generally in sampling sites with high Al, SI, NDVI, WI, AWMSI, and VP and low SI1, BT, BSI, and NEDI. AP was high in sampling sites with high NEDI and LII and low VP. The remaining indicators did not show clear spatial inclination.

\subsubsection{Spatial responses of VHI, SHI, and VSSHI}

The CCA ordination diagrams of islands and sampling sites with the complex factors are shown in Fig. 10. The relationships of the complex factors with axes are the same as for Fig. 9. At island scale, the islands with high VHI and VSSHI always possessed low IA, SRP, NEDI, NP, and AWMSI and high PTM and VP. The high SHIs were observed on islands with high PTM and LII. At site scale, the sampling sites with high VHI and VSSHI were generally in areas with high Al, SI, NDVI, WI, AWMSI, and VP and low SI1, BT, BSI, and NEDI, whereas different values of SHI did not show clear spatial inclination.

\subsubsection{Contributions of different factors to the spatial pattern}

The contributions of the vegetation and soil indicators to the species spatial pattern are shown in Table 7. At island scale, in tree layer, $\mathrm{SE}$, pH, and $\mathrm{MC}$ made the highest three contributions, whereas AP, HH', and TC made the lowest three ones. In shrub layer, $\mathrm{pH}, \mathrm{AK}$, and SE contributed the most, while AP, TC, and Sa showed the lowest contributions. In herb layer, $\mathrm{SE}, \mathrm{pH}$, and TCo made the highest three contributions, and AP, HH', and MC made the lowest three ones. At site scale, the contributions of the indicators greatly changed. In tree layer, $\mathrm{Sa}, \mathrm{HCo}$, and $\mathrm{MC}$ were the indicators exhibiting the highest three contributions, and $\mathrm{HE}$, $\mathrm{SH}^{\prime}$, and TH made the lowest contributions. In shrub layer, Sa, MC, and SH' made the highest three contributions, whereas TC, OM, and TN made the lowest three contributions. In herb layer, $\mathrm{SH}^{\prime}, \mathrm{pH}$, and TCo contributed the most, while AP, MC, and BD showed the lowest three contributions. 
Table 7

Contributions of the vegetation and soil indicators to the species spatial pattern (\%)

\begin{tabular}{|c|c|c|c|c|c|c|}
\hline \multirow[t]{2}{*}{ Indicators } & \multicolumn{3}{|c|}{ Island scale } & \multicolumn{3}{|l|}{ Site scale } \\
\hline & Tree layer & Shrub layer & Herb layer & Tree layer & Shrub layer & Herb layer \\
\hline TCo & 6.21 & 6.70 & 6.38 & 6.20 & 5.94 & 7.47 \\
\hline $\mathrm{TH}^{\prime}$ & 6.36 & 4.64 & 5.47 & 4.23 & 4.66 & 5.47 \\
\hline TE & 6.04 & 5.54 & 6.20 & 4.58 & 4.77 & 5.59 \\
\hline SCo & 6.12 & 7.08 & 6.29 & 5.24 & 6.24 & 5.98 \\
\hline $\mathrm{SH}^{\prime}$ & 6.74 & 6.95 & 6.35 & 4.16 & 7.22 & 7.64 \\
\hline SE & 7.92 & 7.39 & 6.77 & 6.42 & 6.84 & 6.73 \\
\hline $\mathrm{HCo}$ & 4.13 & 5.35 & 5.65 & 7.82 & 5.37 & 4.61 \\
\hline $\mathrm{HH}^{\prime}$ & 1.95 & 4.78 & 3.26 & 6.20 & 4.84 & 6.73 \\
\hline HE & 5.93 & 6.72 & 6.01 & 3.44 & 4.37 & 6.06 \\
\hline $\mathrm{BD}$ & 6.34 & 5.87 & 5.96 & 5.22 & 3.94 & 4.46 \\
\hline $\mathrm{pH}$ & 7.49 & 7.85 & 6.66 & 5.21 & 6.95 & 7.51 \\
\hline MC & 7.06 & 4.73 & 4.67 & 7.09 & 7.28 & 3.36 \\
\hline $\mathrm{Sa}$ & 5.65 & 4.61 & 4.73 & 9.13 & 9.50 & 5.37 \\
\hline TC & 3.23 & 3.37 & 4.87 & 4.77 & 3.04 & 4.60 \\
\hline $\mathrm{TN}$ & 4.92 & 4.64 & 5.84 & 6.33 & 3.91 & 5.41 \\
\hline OM & 5.14 & 4.96 & 5.70 & 4.41 & 3.65 & 4.59 \\
\hline$A P$ & 1.84 & 1.36 & 2.92 & 4.38 & 4.28 & 3.17 \\
\hline AK & 6.93 & 7.44 & 6.26 & 5.17 & 7.20 & 5.24 \\
\hline
\end{tabular}

The contributions of the complex factors to the spatial pattern of vegetation-soil system are shown in Table 8. At island scale, the contributions of PTM, VP, NEDI, SRP, ISI, and IA to the species spatial pattern were distinctly higher than those of the remaining factors. To the vegetation and soil indicators, the contributions of SRP, VP, IA, and NEDI were the highest, those of AWMSI, NP, LII, and PTM were intermediate, and those of CP and ISI were the lowest. At site scale, DTS, VP, and SI2 contributed the most to species spatial pattern in tree layer, SI1, VP, and LII contributed the most in shrub later, and BSI, NDVI, and SI1 contributed the most in herb later. To the vegetation and soil indicators, the contributions of BSI, SI1, NDVI, and Al were much higher than those of the other factors, and those of As and LII were lowest. 
Table 8

Contributions of the complex factors to the spatial pattern of vegetation-soil system (\%)

\begin{tabular}{|c|c|c|c|c|c|c|c|c|c|}
\hline \multirow[t]{2}{*}{ Factors } & \multicolumn{4}{|c|}{ Island scale } & \multirow[t]{2}{*}{ Factors } & \multicolumn{4}{|l|}{ Site scale } \\
\hline & Tree layer & Shrub layer & Herb layer & Indicators & & Tree layer & Shrub layer & Herb layer & Indicators \\
\hline NEDI & 13.54 & 12.83 & 13.11 & 12.07 & NEDI & 6.75 & 7.13 & 7.72 & 7.42 \\
\hline VP & 14.05 & 13.51 & 13.40 & 16.80 & VP & 8.96 & 7.93 & 8.17 & 5.96 \\
\hline $\mathrm{CP}$ & 4.70 & 5.93 & 4.96 & 3.41 & $\mathrm{CP}$ & 7.19 & 4.83 & 4.62 & 2.36 \\
\hline NP & 6.71 & 6.99 & 6.96 & 8.40 & NP & 4.16 & 2.95 & 4.07 & 1.24 \\
\hline AWMSI & 5.83 & 6.34 & 6.53 & 8.92 & AWMSI & 6.44 & 4.83 & 5.32 & 3.26 \\
\hline LII & 4.15 & 9.01 & 7.96 & 8.14 & LII & 1.64 & 7.55 & 1.97 & 0.67 \\
\hline IA & 11.15 & 11.20 & 11.49 & 13.39 & Al & 8.05 & 6.48 & 7.59 & 12.02 \\
\hline ISI & 11.45 & 11.57 & 11.46 & 4.20 & SI & 3.23 & 6.08 & 7.71 & 6.18 \\
\hline PTM & 16.06 & 10.39 & 11.34 & 7.61 & As & 5.73 & 4.64 & 2.84 & 0.56 \\
\hline \multirow[t]{7}{*}{ SRP } & 12.37 & 12.22 & 12.79 & 17.06 & DTS & 10.06 & 6.38 & 4.19 & 1.01 \\
\hline & & & & & NDVI & 6.26 & 7.35 & 8.79 & 13.15 \\
\hline & & & & & SI1 & 5.49 & 8.02 & 8.71 & 13.48 \\
\hline & & & & & $\mathrm{SI} 2$ & 8.47 & 4.43 & 4.37 & 1.80 \\
\hline & & & & & BT & 5.68 & 6.89 & 7.83 & 8.31 \\
\hline & & & & & WI & 6.46 & 7.13 & 6.80 & 7.64 \\
\hline & & & & & BSI & 5.44 & 7.38 & 9.29 & 14.94 \\
\hline
\end{tabular}

\section{Discussion}

\subsection{Species diversity and spatial pattern}

\subsubsection{Species diversity}

A total of 21, 71, and 171 species were recorded in tree, shrub, and herb layers, respectively, in the 111 sampling sites in the Dongtou Archipelago. The species diversity was generally low in tree layer and high in shrub and herb layers compared with other similar islands in China: (1) the 10 inhabited islands in the Miaodao Archipelago, which are typical rocky islands in North China and had tree, shrub, and herb species numbers of 15, 41, and 160, respectively, in 120 sampling sites (Chi et al., 2016, 2018); (2) the Chongming Island, which is the largest sandy island in the world and possessed tree, shrub, and herb species numbers of 32, 4, and 125, respectively, in 110 sampling sites (Huang et al., 2008); (3) the Zhoushan Archipelago, which is the largest archipelago in China and had tree, shrub, and herb species numbers of 47, 44, and 40, respectively, in 70 sampling sites (Li et al., 2012); and (4) the 12 uninhabited islands in Xiamen City, which are typical uninhabited islands in South China and exhibited 78, 109, and 150 species in tree, shrub, and herb layers, respectively by thoroughly investigating the entire areas (Xiao et al., 2018). In this study, the species in tree layer were mostly artificially planted with specific species, of which Casuarina equisetifolia is the most dominant tree species in the study area and one of the important plantation species in coastal areas of Southeast China (Huang et al., 2003). It is characterized by fast growth rate and high adaptability and has been planted in a large scale since the 1960 s. In recent decades, it greatly helped resist the disasters of wind and storm surge and improve the coastal ecosystem stability (Huang et al., 2012). Correspondingly, the species diversity was generally low in tree layer. The shrub and herb species were partly or barely artificially planted and grew well in the warm and wet climate, thereby showing a high species diversity. The dominant species in tree layer were similar, yet those in shrub and herb layers changed and greatly changed, respectively, between sandy and rocky islands. Humans planted the trees using specific several species over the study area, resulting in the homogeneity of dominant species in tree layer. The herb species were mostly naturally developed. Thus, the considerable differences in natural conditions between sandy and rocky islands generated distinct heterogeneity of dominant species. The shrub species were partly artificially planted and partly naturally developed, thereby resulting in the coexistence of similarity and difference of dominant species between sandy and rocky islands.

The species composition was compared with that in the entire Wenzhou City and the Yandang Mountain. The former covers the study area and was used to represent the regional characteristics (Xiong et al., 2017); the latter is located in the alongshore mainland and was used to represent the species composition of the neighboring mainland (Chen et al., 2018b). At family level, the common families were similar in the three regions, that is, Composita occupied the most species number and Gramineae was one of the common families. At genus level, the similarity of common genera could still be observed, i.e., Polygonum was the common genus in the three regions. At species level, the species lists were generally identical because of the close geographical position and frequent species communication (Chi et al., 2019a). However, species endemic to the study area existed due to the unique natural conditions of the sandy and rocky islands. For instance, Tamarix chinensis, which is a typical wetland plant in North China, was observed in several islands of the study area and was absent in the other areas in Zhejiang Province. 


\subsubsection{Species spatial pattern}

The CCA ordination diagrams for the species showed that the dominant species were generally distributed in a concentrated form near the origin in the three layers at island scale, indicating the insensitivity of species to the environmental factors at this scale (Fig. 7). Though great differences in dominant species exited between sandy and rocky islands, those among the nine rocky islands were not distinct, resulting in the insensitivity. At site scale, the sensitivities of the species to the environmental factors increased along tree, shrub, and herb layers according to Fig. 8 . This could also be explained by the artificiality. In the environmental factors, vegetation indictors were inherently related to the species data, and the remaining factors, including soil indicators and the complex factors, could be considered the habitat factors. Since the species only exhibited sensitivity in shrub and herb layers at site scale, the environmental factors for the two layers at this scale were discussed. In shrub layer, SH', SE, and SCo made the highest three contributions in the vegetation indicators, and Sa, MC, and AK were the most important soil indicators. In herb layer, SH', TCo, and SE contributed the most in the vegetation indicators, whereas $\mathrm{pH}$, TN, and Sa were relatively important soil indicators. Sa was an effective indicator for salinization and greatly influenced the species spatial pattern in the study area, especially on the sandy island. In both layers, ecological indices and landscape pattern made more contributions than terrain condition did, of which BSI, NDVI, SI1, VP, and NEDI were the most important.

The species-area relationship is one of the core issues in biodiversity study, and the island provides a natural laboratory for this type of study, thereby generating an important theory, that is, island biogeography (MacArchur and Wilson, 1963, 1967; Whittaker and Fernández-Palacios, 2007; Whittaker et al., 2017). The sandy-rocky island chain could serve as a new and special experimental base for the study of species-area relationship, which was then analyzed for species in each and all of the three layers using a log transformed power model (Triantis et al., 2012; Matthews et al., 2016; Chi et al., 2019a). The $\mathrm{R}^{2}$ in herb layer was much higher than that in tree and shrub layers, and the slope of trend line increased along the tree, shrub, and herb layers (Figs. 11a, 11b, and 11c). The $R^{2}$ and slope of trend line for all species in the three layers combined the characteristics of those in different layers, that is, they were higher than those in tree and shrub layers and lower that those in herb layer (Fig. 11d). It indicated that herb species responded more sensitively to IA that tree and shrub layers, which was in accordance with the study by Chi et al. (2016). In addition, the slope of trend line for all species was generally high compared with the studies by Panitsa et al. (2006), Sfenthourakis and Panitsa (2012), and Chi et al. (2019a). The IA determined the upper limit of biodiversity on these islands, though communications among the islands were frequent.

\subsection{Influencing factors of the vegetation-soil system at the dual scales}

\subsubsection{Island scale}

From the perspective of single factor, the sum of the $\mathrm{R}^{2}$ for a factor was considered as its total influence, and the results were highly identical to the results from the perspective of complex factors (Tables 5 and 8). SRP, VP, IA, and NEDI were the factors that possessed the highest influences, whereas ISI and CP had the lowest influences. The remaining factors, including AWMSI, NP, LII, and PTM, were in an intermediate level. SRP and NEDI mainly referred to the anthropogenic factors. The SRP denoted the sea reclamation, which is a controversial activity that expands spaces for human survival and development but substantially damaged the ocean ecosystems in aspects of geomorphology, hydrodynamics, habitat, and pollution (Lin et al., 2016; Chen et al., 2018c). A total of 16 vegetation and soil indicators responded sensitively to SRP, of which $\mathrm{HCo}, \mathrm{BD}, \mathrm{pH}, \mathrm{MC}$, Sa, and AK showed increasing trends, and the other factors showed decreasing trends. Overall, the VHI, SHI, and VSSHI were all sensitive and showed decreasing trends, indicating that the increase in SRP resulted in the decrease in the health of the vegetation-soil system. The NEDI indicated the damage degree of natural ecosystem caused by various island uses, including constructions of buildings, ports, roads, and factories, as well as agricultural activities (Chi et al. 2019c). Most of the sensitive indicators negatively responded to NEDI. The VHI and VSSHI were sensitive and exhibited negative trends, whereas the SHI was insensitive. The IA was closely related to SRP and SESI. The sea reclamations were mainly conducted in large islands, including Is.1, Is.2, Is. 5, and Is. 8, of which Is. 1 possessed the highest IA and SRP. Besides, larger islands always carried higher human activity intensity and suffered from more damage, which was proven in the previous study (Chi et al., 2019c). Therefore, similar to the results for SRP and NEDI, most of the indicators, as well as the VHI and VSSHI, showed clear decreasing trends responding to IA. The VP referred to the total coverage of forest, grassland, and wetland vegetation. It is a common parameter to judge the overall ecological condition in a region and involves a series of ecological processes (Zhou et al., 2006). In this study, 11 indicators were sensitive to VP, most of which showed increasing trends. The increase in VP resulted in the increase in VHI and VSSHI. The ISI and CP exhibited little influence on the vegetation-soil system. The low influence of ISI was in accordance with the previous studies by Chi et al. $(2018,2019$ a), and indicated that the ISI was not a key factor for islands that were occupied by human activities. The low influence of $\mathrm{CP}$ could be explained by the small difference of $\mathrm{CP}$ across islands.

Different vegetation and soil indicators exhibited different sensitivities to the factors. In term of the sum of $\mathrm{R}^{2}$ from the perspective of single factor, vegetation indicators showed higher sensitivities than soil indicators, and the TE and AP possessed the highest and lowest $\mathrm{R}^{2}$, respectively. The VHI, VSSHI, and SHI were in the descending order of $\mathrm{R}^{2}$, which was in accordance with the results from the perspective of complex factors in Fig. 10, that is, the VHI and VSSHI responded more sensitively to the factors than the SHI did. Generally, high VP and PTM and low IA, SRP, NEDI, NP, and AWMSI indicated high VHI and VSSHI, and high PTM and LII resulted in high SHI.

\subsubsection{Site scale}

The influences of the factors from the two perspectives were also in accordance with each other at site scale, as exhibited by the sum of CCs from the perspective of single factor and the contributions from the perspective of complex factors. The influences of ecological indices were much higher than those of terrain condition and landscape pattern. BSI, SI1, and NDVI achieved the highest influences of all the factors, and they represented the island ecosystem in different aspects of land surface aridity, soil quality, and vegetation conditions, respectively. Most of the vegetation and soil indicators, as well as the VHI, SHI, and VSSHI, negatively responded to BSI and SI1 and positively responded to NDVI. The results validated the high sensitivity of the vegetation-soil system to the three ecological indices, which was in accordance with the studies by Hu and Xu (2018) and Chi et al. (2019b). In the terrain condition, Al showed a relative 
high influence, and the vegetation-soil system was generally healthier when the Al was higher. In the study area, the areas with low Al were always occupied by urban constructions and farming activities, and those with high Al were covered by vegetation, thereby rendering the vegetation-soil system sensitive to Al. The similar situation also occurred on the Miaodao Archipelago in North China, that is, the terrain condition influenced the vegetation through affecting the spatial pattern of human exploitations (Chi et al., 2016). Although VP and NEDI showed intermediate influences, the landscape pattern factors were generally weak in influencing the system at site scale. Different from the other factors, the landscape pattern factors exert influences at different scales, and the influences may change with the change in the scale, which is called the scale effect (Wu, 2000; Buffa et al., 2018). In this study, the landscape pattern factors were calculated at island and site scales; at site scale, they were calculated at four scales of 50, $100 \mathrm{~m}, 150 \mathrm{~m}$, and $200 \mathrm{~m}$. The spatial responses at different scales showed that the influences of landscape pattern factors were higher at island scale than at site scale, and at the $200 \mathrm{~m}$ scale than at the other scales within the site scale, which indicated that the vegetation-soil system responded more sensitively to the landscape pattern at a larger scale.

The sensitivities of the vegetation and soil indicators showed consistent characteristics at island and site scales. The vegetation indicators in tree and shrub layers possessed high CCs in Table 6 and showed distinct spatial inclinations in Fig. 9(b), and the vegetation indicators in herb layer and most of the soil indicators were not sensitive to the factors. Similar to the results at island scale, the VHI and VSSHI exhibited higher sensitivities than SHI, and the SHI responded insensitively to the factors from the perspective of complex factors at site scale. The VHI and VSSHI generally increased with the increase in Al, SI, NDVI, WI, AWMSI, and VP and the decrease in SI1, BT, BSI, and NEDI.

\section{Conclusions}

A sandy-rocky island chain in the Dongtou Archipelago in South China was selected to demonstrate the study on the spatial responses of the vegetation-soil system to complex factors across different types of islands. A total of 18 indictors were used to represent different aspects of the vegetation-soil system and three new indices, namely, VHI, SHI, and VSSHI, were proposed to measure the overall characteristics of the system. Four types of factors, including island basic factors, landscape pattern, terrain condition, and ecological indices, were identified to cover all aspects of potential factors of the system. Then, the spatial responses of the system to the complex factors were analyzed at two spatial scales (island and site scales), from two perspectives (single factor and complex factors), and using three approaches (regression analysis, correlation analysis, and CCA ordination). The results revealed the spatial characteristics of the vegetation-soil system across different types of islands, clarified the spatial responses of the system to complex factors at the dual scales, and identified the main influencing factors of the system, which could provide reference for island conservation and contribute to the development of island ecology.

The results in the island chain indicated that the species diversity was generally low in tree layer and high in shrub and herb layers. The species sensitively responded to the factors only at site scale in shrub and herb layers, which was caused by the difference of artificiality in different layers. At island scale, high VHI and VSSHI were always observed on islands with high VP and PTM and low IA, SRP, NEDI, NP, and AWMSI, and islands with high PTM and LII always possessed high SHI. The factors of SRP, VP, IA, and NEDI were the most important. At site scale, the VHI and VSSHI generally increased with the increase in Al, SI, NDVI, WI, AWMSI, and VP and the decrease in SI1, BT, BSI, and NEDI. Three ecological indices, that is, BSI, SI1, and NDVI, achieved the highest influences of all the factors. The vegetation-soil system showed similar and different responses to the complex factors across the dual scales. The similarity was represented by the higher sensitivities of VHI and VSSHI compared with that of SHI at both scales, and the difference mainly indicated that the influences of landscape pattern factors distinctly decreased along the scales from island to site.

\section{Declarations Funding}

and Conflicts of interests

\section{References}

1. Allbed A, Kumar L, Aldakheel YY (2014) Assessing soil salinity using soil salinity and vegetation indices derived from IKONOS high-spatial resolution imageries: Applications in a date palm dominated region. Geoderma 230-231:1-8

2. Aragüés R, Medina ET, Zribi W, Clavería I, Álvaro-Fuentes J, Faci J (2014) Soil salinization as a threat to the sustainability of deficit irrigation under present and expected climate change scenarios. Irrig Sci 33:67-79

3. Batjes NH (1996) Total carbon and nitrogen in the soils of the world. Eur J Soil Sci 65(1):2-3

4. Borges PAV, Cardoso P, Kreft H, Whittaker RJ, Fattorini S, Emerson BC, Gil A, Gillespie RG, Matthews TJ, Santos AMC, Steinbauer MJ, Thébaud C, Ah-Peng C, Amorim IR, Aranda SC, Arroz AM, Azevedo JMN, Boieiro M, Borda-de-Água L, Carvalho JC, Elias RB, Fernández-Palacios JM, Florencio M, GonzálezMancebo JM, Heaney LR, Hortal J, Kueffer C, Lequette B, Martín-Esquivel JL, López H, Lamelas-López L, Marcelino J, Nunes R, Oromí P, Patiño J, Pérez AJ, Rego C, Ribeiro SP, Rigal F, Rodrigues P, Rominger AJ, Santos-Reis M, Schaefer H, Sérgio C, Serrano ARM, Sim-Sim M, Stephenson PJ, Soares AO, Strasberg D, Vanderporten A, Vieira V, Gabriel R (2018) Global Island Monitoring Scheme (GIMS): a proposal for the long-term coordinated survey and monitoring of native island forest biota. Biodivers. Conserv. 27, 2567-2586

5. Buffa G, Vecchio SD, Fantinato E, Milano V (2018) Local versus landscape-scale effects of anthropogenic land-use on forest species richness. Acta Oecol 86:49-56

6. Cassel F, Goorahoo D, Sharmasarkar S (2015) Salinization and yield potential of a saltladen Californian soil: an in situ geophysical analysis. Water Air Soil Poll 226:422

Page $17 / 25$ 
7. Chang C, Wang H, Huang C (2013) Impacts of vegetation onset time on the net primary productivity in a mountainous island in Pacific Asia. Environ Res Lett 8(4):045030

8. Chen S, Wang W, Xu W, Wang Y, Wan H, Chen D, Tang Z, Tang X, Zhou G, Xie Z, Zhou D, Shangguan Z, Huang J, He J, Wang Y, Sheng J, Tang L, Li X, Dong M, Wu Y, Wang Q, Wang Z, Wu J, Chapin III, Bai FS, Y., 2018a. Plant diversity enhances productivity and soil carbon storage. Proc. Natl. Acad. Sci. U. S. A. $115,4027-4032$

9. Chen W, Xiong X, Zheng Y, Jin X (2018b) Floristic analysis of the seed plants from Yandang Mountain of Yueqing, Zhejiang. Journal of Zhejiang University (ScienceEdition) 45:119-126

10. Chen Y, Wei Y, Peng L (2018c) Ecological technology model and path of seaport reclamation construction. Ocean Coast Manage 165:244-257

11. Chi Y, Shi H, Wang X, Qin X, Zheng W, Peng S (2016) Impact factors identification of spatial heterogeneity of herbaceous plant diversity on five southern islands of Miaodao Archipelago in North China. Chin J Oceanol Limnol 34(5):937-951

12. Chi Y, Shi H, Zheng W, Sun J (2017) Multiple gradient effects on spatial distribution of island soil microbial biomass. Eur J Soil Biol 83:65-75

13. Chi Y, Shi H, Zheng W, Wang E (2018) Archipelagic landscape patterns and their ecological effects in multiple scales. Ocean Coast Manage 152:120-134

14. Chi Y, Sun J, Fu Z, Xie Z (2019a) Spatial pattern of plant diversity in a group of uninhabited islands from the perspectives of island and site scales. Sci Total Environ 664:334-346

15. Chi Y, Zhang Z, Gao J, Xie Z, Zhao M, Wang E (2019b) Evaluating landscape ecological sensitivity of an estuarine island based on landscape pattern across temporal and spatial scales. Ecol Indic 101:221-237

16. Chi Y, Zhang Z, Xie Z, Wang J (2019c) How human activities influence the island ecosystem through damaging the natural ecosystem and supporting the social ecosystem? J. Clean. Prod. Under Review

17. Chu Z, Yang X, Feng X, Fan D, Li Y, Shen X, Miao A (2013) Temporal and spatial changes in coastline movement of the Yangtze delta during 1974-2010. J Asian Earth Sci 66:166-174

18. Dai F, Lee C, Li J, Xu Z (2001) Assessment of landslide susceptibility on the natural terrain of Lantau Island, Hong Kong. Environ Geol 40(3):381-391

19. Ding C, Zhang H, Li X, Li W, Gao Y (2017) Quantitative assessment of water conservation function of the natural spruce forest in the central Tianshan Mountains: a case study of the Urumqi River Basin. Acta Ecol Sin 37(11):3733-3743

20. Douaoui AEK, Nicolas H, Walter C (2006) Detecting salinity hazards within a semiarid context by means of combining soil and remote-sensing data. Geoderma 134:217-230

21. Eldridge MDB, Meek PD, Johnson RN (2014) Taxonomic uncertainty and the loss of biodiversity on Christmas Island. Indian Ocean Conserv Biol 28(2):572-579

22. Galloway JN, Townsend AR, Erisman JW, Bekunda M, Cai Z, Freney JR, Martinelli LA, Seitzinger SP, Sutton MA (2008) Transformation of the nitrogen cycle: recent trends, questions, and potential solutions. Science 320:889-892

23. Gao W, Liu L, Liu J, Xu Y, Li P, Li PY, Xu G (2016) Formation mechanism and evolution of Beichangshan Island coast landslide in Shandong Province. Acta Oceanol $\operatorname{Sin}$ 38(9):100-109

24. Gil A, Fonseca C, Benedicto-Royuela J (2018) Land cover trade-offs in small oceanic islands: a temporal analysis of Pico Island, Azores. Land Degrad Dev 29:349-360

25. Grimm R, Behrens T, Märker M, Elsenbeer. H (2008) Soil organic carbon concentrations and stocks on Barro Colorado Island-Digital soil mapping using Random Forests analysis. Geoderma 146(1):102-113

26. Hattermann D, Bernhardt-Römermann M, Otte A, Eckstein RL (2018) New insights into island vegetation composition and species diversity-Consistent and conditional responses across contrasting insular habitats at the plot-scale. PLoS ONE 13(7):e0200191

27. Hu X, Xu H (2018) A new remote sensing index for assessing the spatial heterogeneity in urban ecological quality: a case from Fuzhou City, China. Ecol Indic 89:11-21

28. Huang B, Ouyang Z, Zheng H, Zhang H, Wang X (2008) Construction of an eco-island: a case study of Chongming Island, China. Ocean Coast Manag $51(8-9): 575-588$

29. Huang J, Cai S, He X, Ding B, Zeng L (2012) Advance in occurrence present and control methods of major pest in coastal protection forest on the coast of Southeast China. Journal of Fujian Forestry Science Technology 39:165-167

30. Huang Y, Zheng D, Fang Z, Xie J, Sha J (2003) Study on the ecological and economical benefits of Casuarina equisetifolia shelterbelt in the coast of Fujian. Scientia Silvae Sinicae 39:31-35

31. Koutroulis AG, Vrohidou AEK, Tsanis IK (2011) Spatiotemporal characteristics of meteorological drought for the island of Crete. J Hydrometeorol 12(2):206-226

32. Kura NU, Ramli MF, Ibrahim S, Wan NAS, Aris AZ (2014) An integrated assessment of seawater intrusion in a small tropical island using geophysical, geochemical, and geostatistical techniques. Environ Sci Pollut Res Int 21(11):7047-7064

33. Li J, Zhang J, Zou C, Liu Z (2012) Type and sort of plant communities in Putuo Mountains under tourism development. Scientia Silvae Sinica 48(7):174181

34. Li S, Su P, Zhang H, Zhou Z, Xie T, Shi R, Gou W (2018) Distribution patterns of desert plant diversity and relationship to soil properties in the Heihe River Basin, China. Ecosphere 9(7):e02355

35. Lin L, Liu D, Liu Z, Gao H (2016) Impact of land reclamation on marine hydrodynamic and ecological environment. Acta Oceanol Sin 38:1-11 
36. Lin S, Liu C, Huang W, Lin S, Yen T, Wang H, Kuo J, Lee Y (2010) Developing a yearly warning index to assess the climatic impact on the water resources of Taiwan, a complex-terrain island. J Hydrol 390(1-2):13-22

37. MacArchur RH, Wilson EO (1963) An equilibrium theory of insular zoogeography. Evolution 37:373-387

38. MacArchur RH, Wilson EO (1967) The Theory of Island Biogeography. Princeton University Press, Princeton

39. Médail F (2017) The specific vulnerability of plant biodiversity and vegetation on Mediterranean islands in the face of global change. Reg Environ Change 17:1775-1790

40. Noone S, Broderick C, Duffy C, Matthews T, Wilby RL, Murphy C (2017) A 250-year drought catalogue for the island of Ireland (1765-2015). Int J Climatol 37:239-254

41. Ouyang Z, Wang R, Zhao J (1999) Ecosystem services and their economic valuation. Chin J Appl Ecol 10(5):635-640

42. Panitsa M, Tzanoudakis D, Triantis K, Sfenthourakis S (2006) Patterns of species richness on very small islands: the plants of the Aegean archipelago. J Biogeogr 33(7):1223-1234

43. Qin D, Chao Z, Wang K (2012) Suitability analysis for greenway planning in China: an example of Chongming Island. Environ Manage 49(1):96-110

44. Reeves DW (1997) The role of soil organic matter in maintaining soil quality in continuous cropping systems. Soil Tillage Res 43:131-167

45. Scudiero E, Skaggs TH, Corwin DL (2014) Regional scale soil salinity evaluation using Landsat 7, western San Joaquin Valley, California, USA. Geoderma Reg. 2-3, 82-90

46. Sfenthourakis S, Panitsa M (2012) From plots to islands: species diversity at different scales. J Biogeogr 39(4):750-759

47. Thies C, Tscharntke T (1999) Landscape structure and biological control in agroecosystems. Science 285(5429):893-895

48. Tian B, Zhang L, Wang X, Zhou Y, Wen Z (2010) Forecasting the effects of sea-level rise at Chongming Dongtan Nature Reserve in the Yangtze Delta, Shanghai, China. Ecol Eng 36(10):1383-1388

49. Tilman D, Reich PB, Knops JMH (2006) Biodiversity and ecosystem stability in a decade-long grassland experiment. Nature 441:629-632

50. Triantis KA, Guilhaumon F, Whittaker RJ (2012) The island species-area relationship: Biology and statistics. J Biogeogr 39(2):215-231

51. Wang H, Hsieh YP, Harwell MA, Huang W (2007) Modeling soil salinity distribution along topographic gradients in tidal salt marshes in Atlantic and Gulf coastal regions. Ecol Model 201:429-439

52. Wardle DA, Yeates GW, Barker GM, Bellingham PJ, Bonner KI, Williamson WM (2003) Island biology and ecosystem functioning in epiphytic soil communities. Science 301:1717-1720

53. Weigelt P, Jetz W, Kreft H (2013) Bioclimatic and physical characterization of the world's islands. P Natl Acad Sci USA 110(38):15307-15312

54. Weigelt P, Steinbauer MJ, Cabral JS, Kreft H (2016) Late Quaternary climate change shapes island biodiversity. Nature 532:99-102

55. Whittaker RJ, Fernández-Palacios JM (2007) Island Biogeography: Ecology, Evolution, and Conservation, 2nd edn. Oxford University Press, Oxford

56. Whittaker RJ, Fernández-Palacios JM, Matthews TJ, Borregaard MK, Triantis KA (2017) Island biogeography: taking the long view of nature's laboratories. Science 357:eaam8326

57. Wu J (2000) Landscape Ecology: Pattern, Process, Scale and Hierarchy. Higher Education Press, Beijing

58. Xiao L, Zhang L, Yang S, Zheng Z, Jiang. D (2018) Flora and species composition similarity of the uninhabited islands in the nearshore Xiamen. Biodivers Sci 26(11):1212-1222

59. Xie Z, Li X, Zhang Y, Chen S (2018) Accelerated expansion of built-up area after bridge connection with mainland: a case study of Zhujiajian Island. Ocean Coast Manag 152:62-69

60. Xiong X, Chen X, Hu R, Zhu S, Tao Z, Zhou Z, Ding B (2017) Floristic analysis of seed plants in Wenzhou Area, southeastern Zhejiang, China. Journal of Zhejiang University (Science Edition) 44:446-455

61. Zhang Y, Liu K, Guo J, Ma H (2013) Features of island ports and their classification in China: Taking Yangshan Port Island and Marine Island County as an example. Geogr Res 32:1095-1102

62. Zheng Z, Du S, Wang Y, Wang Q (2018) Mining the regularity of landscape-structure heterogeneity to improve urban land-cover mapping. Remote Sens. Environ. 214

63. Zhou Z, Shangguan Z, Zhao D (2006) Modeling vegetation coverage and soil erosion in the Loess Plateau Area of China. Ecol Model 198:263-268

\section{Figures}




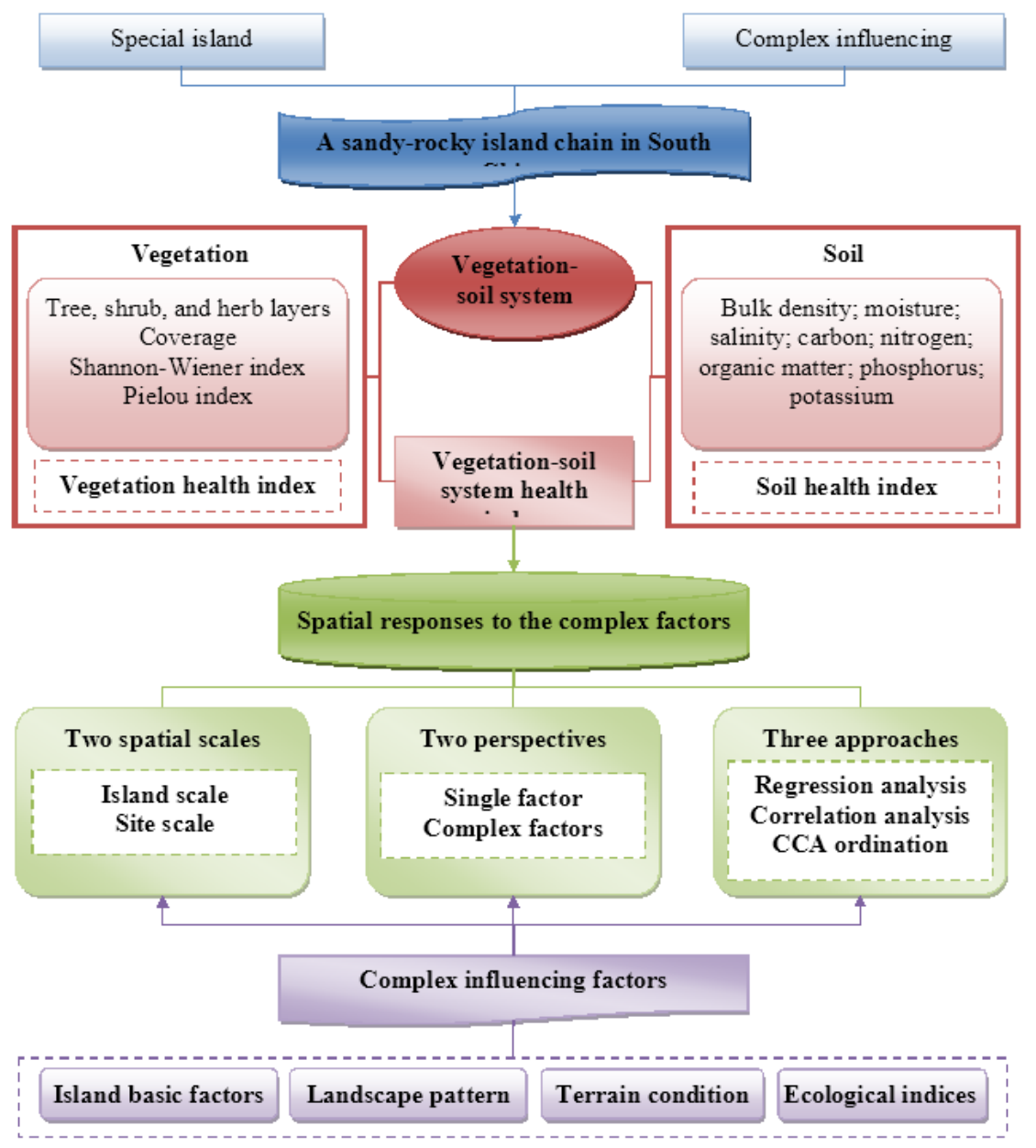

Figure 1

Framework for identifying the spatial responses of vegetation-soil system to complex factors in a sandy-rocky island chain

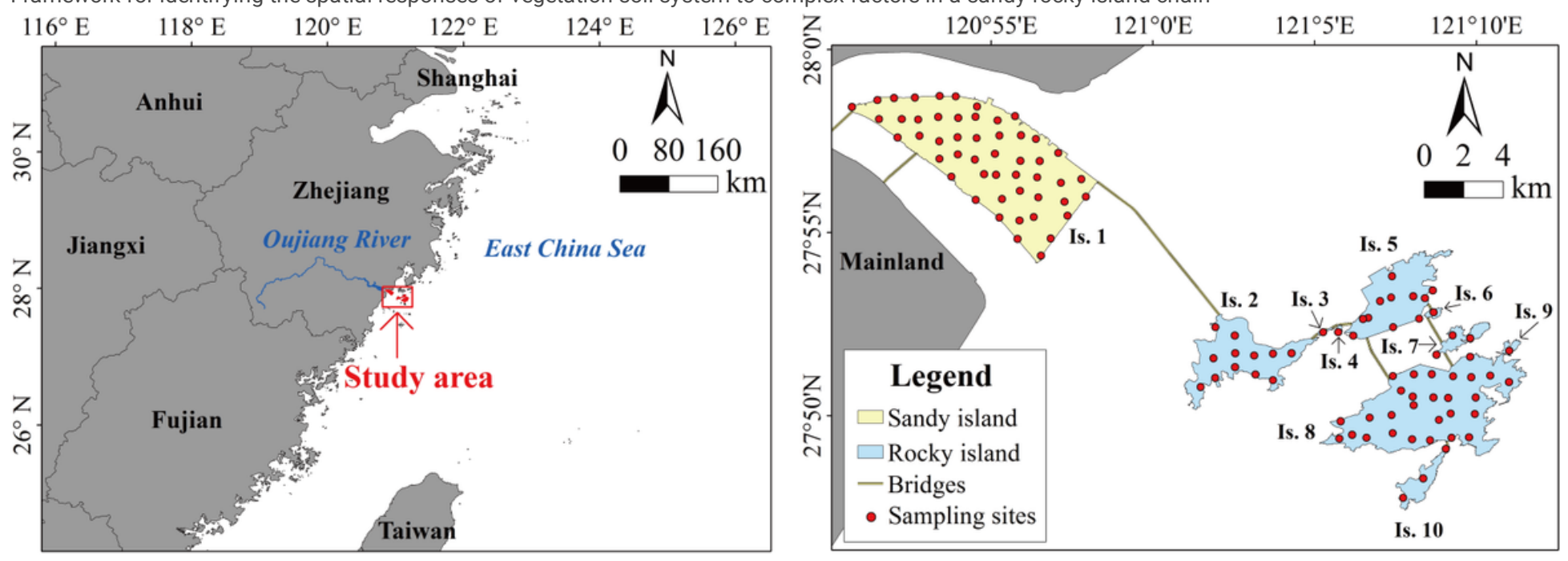

Figure 2

Location (left), island composition (right), and sampling sites (right) of the study area: Is. 1: Lingkun Island; Is. 2: Niyu Island; Is. 3: Qianmenshan Island; Is. 4: Shenmenshan Island; Is. 5: Zhuangyuan'ao Island; Is. 6: Huagang Island; Is. 7: Dasanpan Island; Is. 8: Dongtou Island; Is. 9: Shengli'ao Island; Is. 10: Banping Island. Is. 1 is a sandy island, and the others are rocky islands. All the islands and the mainland are connected by the bridges and the sequence number of the island was assigned using an ascending order along the bridges from the mainland. The location and island composition were quoted from a previous relevant study by the authors (Chi et al., 2019a). 

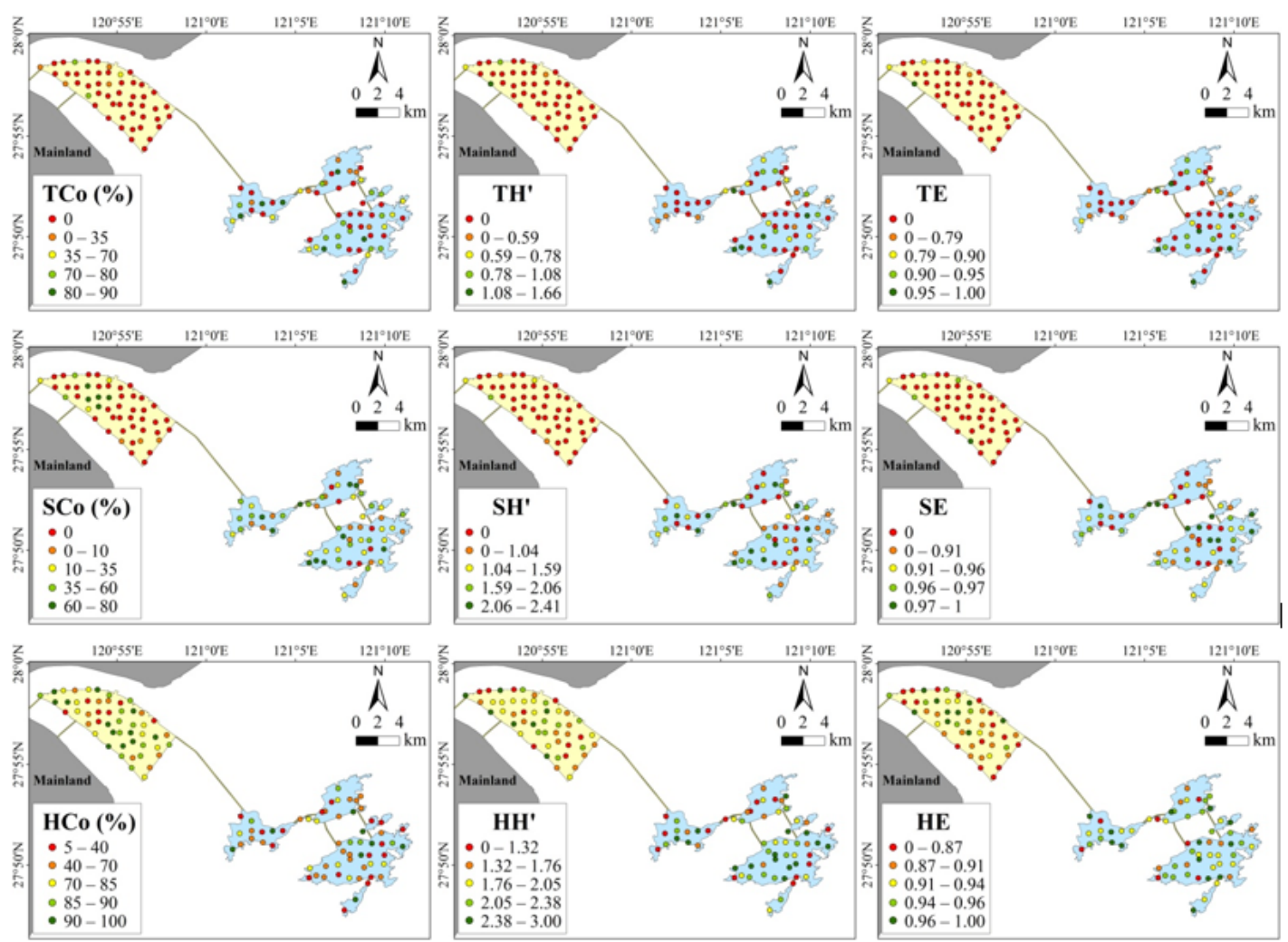

Figure 3

Spatial distributions of vegetation indicators at site scale: The legends were divided using a quantile method in ascending order of indicator values. The abbreviations for the indicators are the same as for Table 4 .
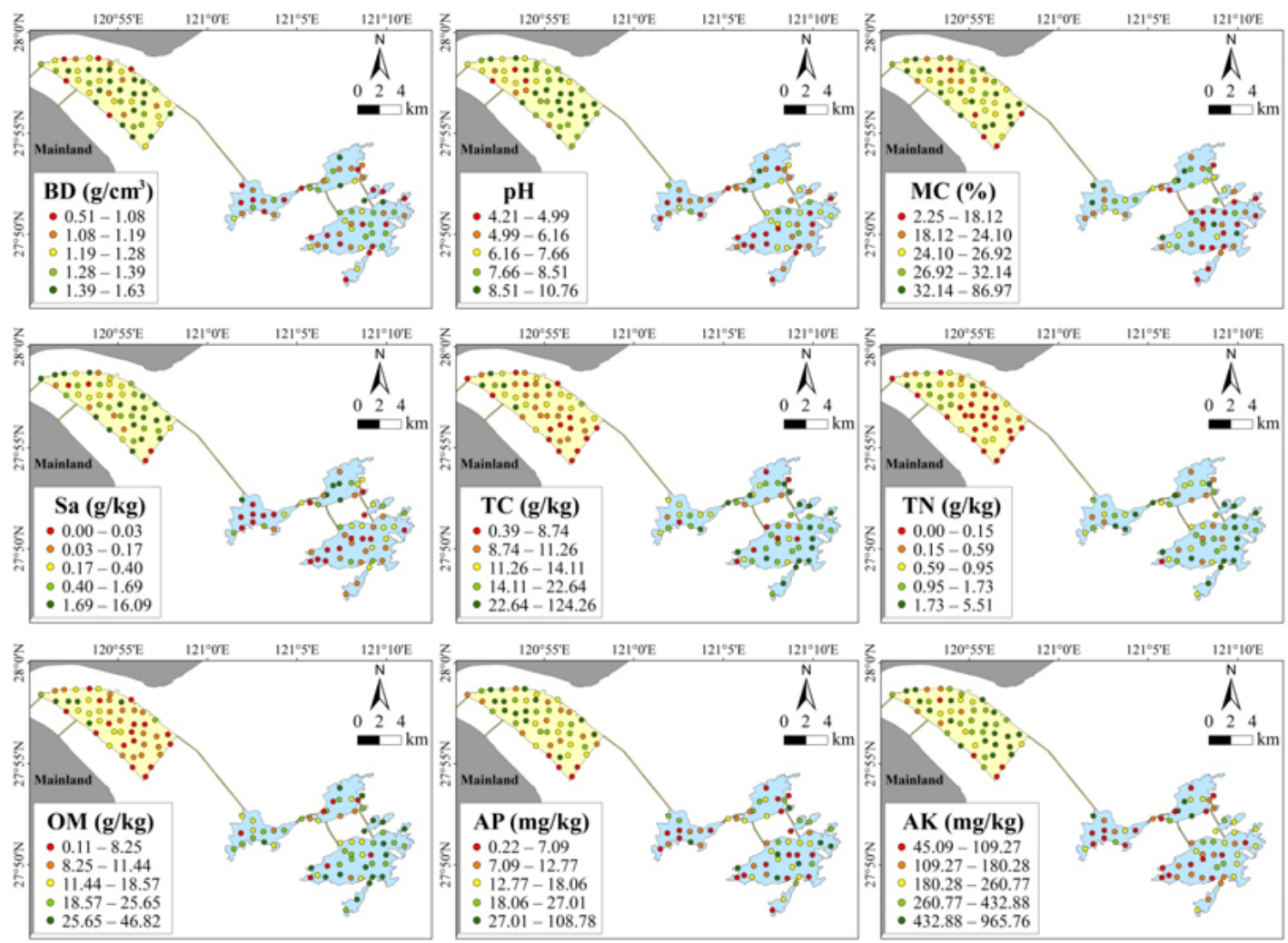

Figure 4 
Spatial distributions of soil indicators at site scale: The abbreviations for the indicators are the same as for Table 4 . The legends were divided using a quantile method in ascending order of indicator values.

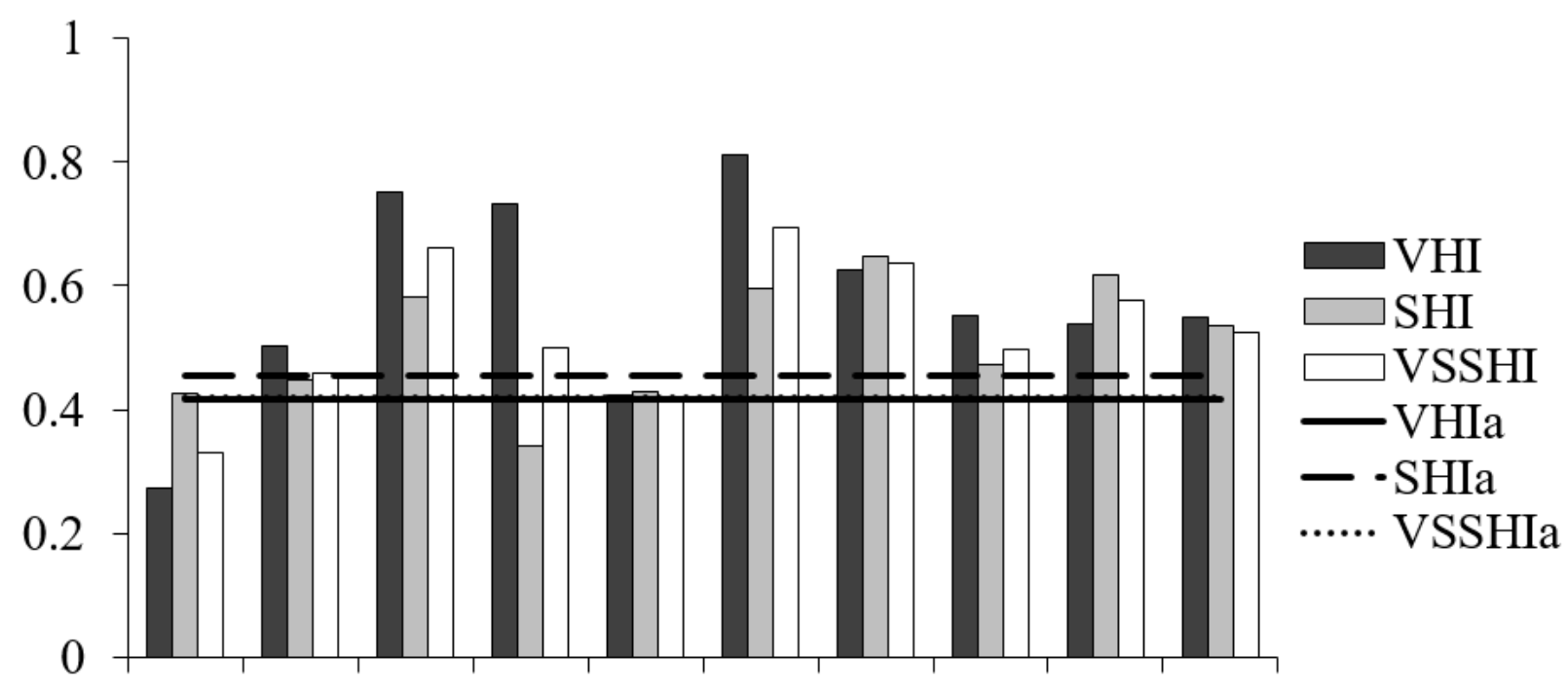

Is. 1 Is. 2 Is. 3 Is. 4 Is. 5 Is. 6 Is. 7 Is. 8 Is. 9 Is. 10

Figure 5

VHI, SHI, and VSSHI on different islands: VHla, SHla, and VSSHla indicate the average values of VHI, SHI, and VSSHI in the entire study area, respectively.

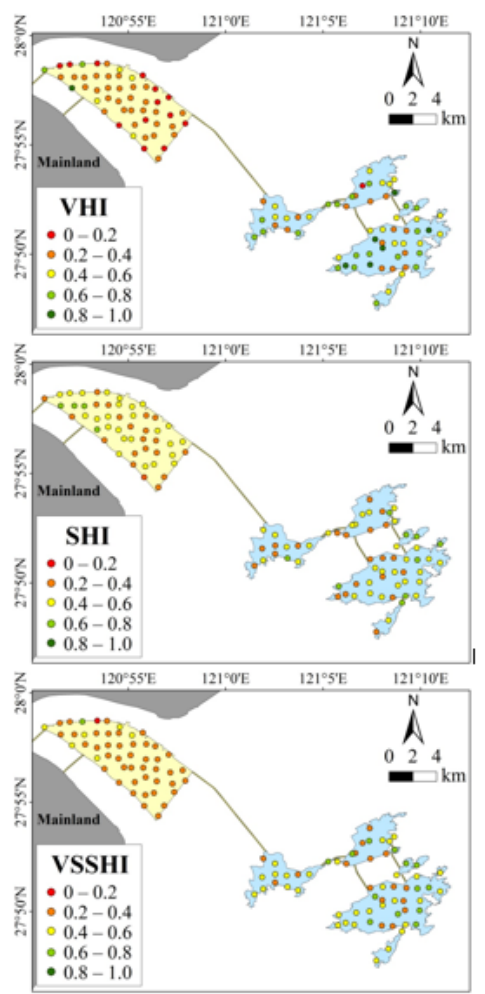

Figure 6

Spatial distributions of VHI, SHI, and VSSHI at site scale: VHI: vegetation health index; SHI: soil health index; VSSHI: vegetation-soil system health index. 

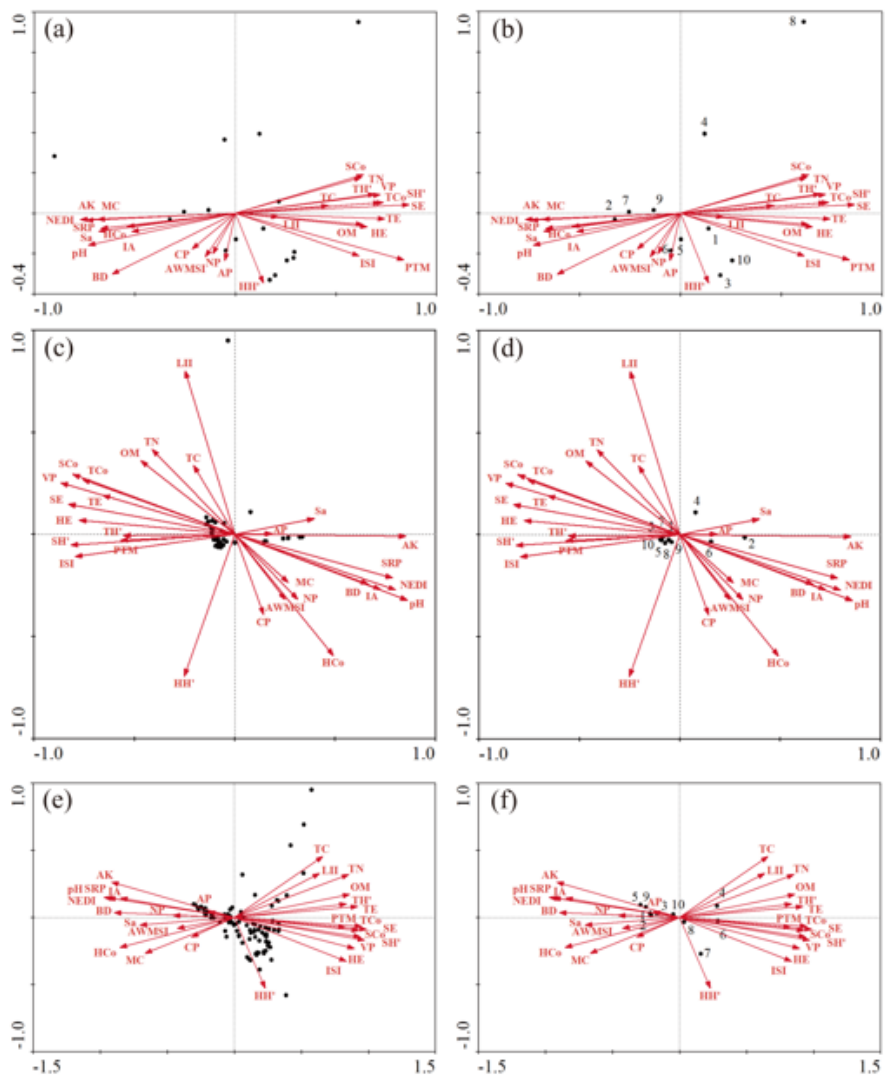

Figure 7

CCA ordination diagrams of species with environmental variables at island scale: (a), (c), and (e) refer to all species in tree, shrub, and herb layers, respectively; (b), (d), and (f) denote dominant species in tree, shrub, and herb layers, respectively, and the dominant species numbers of 1-10 indicate the corresponding dominant species in Table 2. The environmental variables include the complex factors, as well as the vegetation and soil indicators; the abbreviations for them are the same as for Tables 1 and 4.
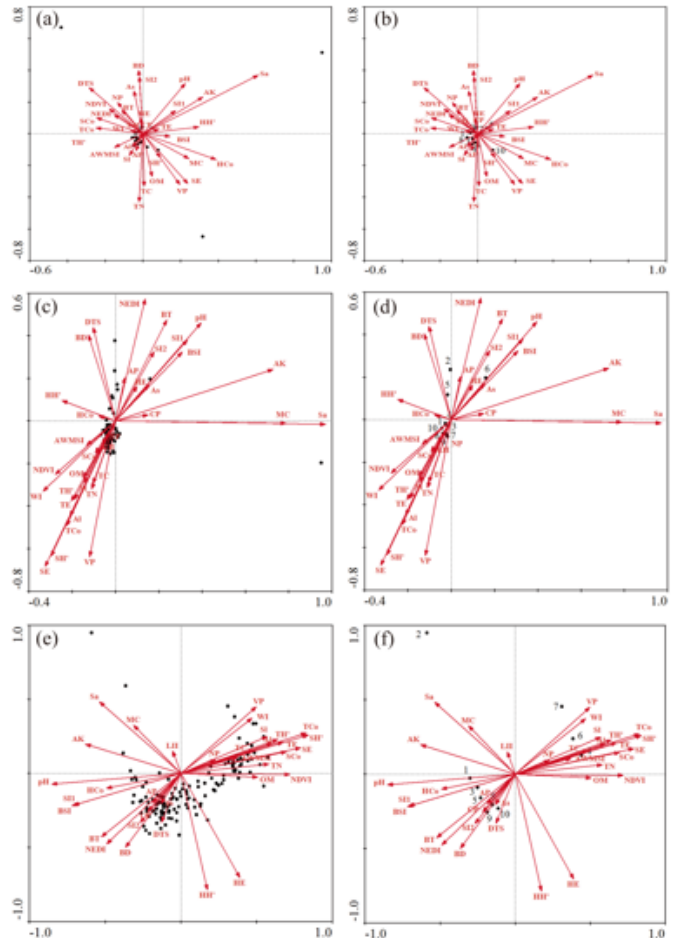

Figure 8

Page $23 / 25$ 
CCA ordination diagrams of species with environmental variables at site scale: (a), (c), and (e) refer to all species in tree, shrub, and herb layers, respectively; (b), (d), and (f) denote dominant species in tree, shrub, and herb layers, respectively.
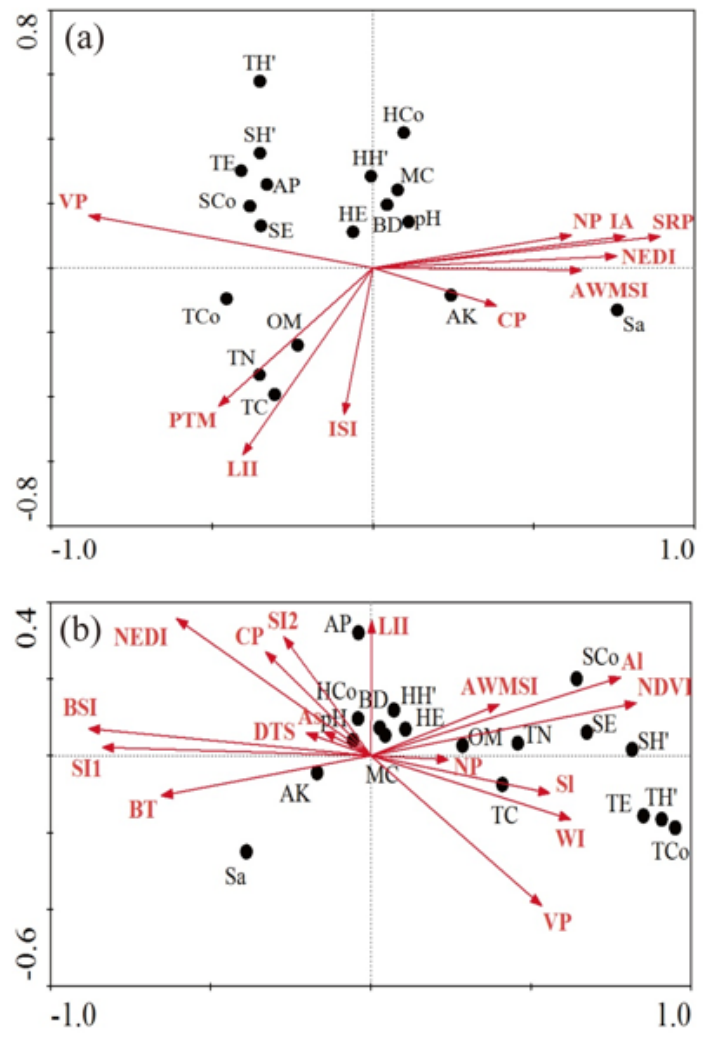

\section{Figure 9}

CCA ordination diagrams of vegetation and soil indicators with the complex factors at island (a) and site (b) scales: The abbreviations for the indicators and factors are the same as for Tables 1 and 4 .
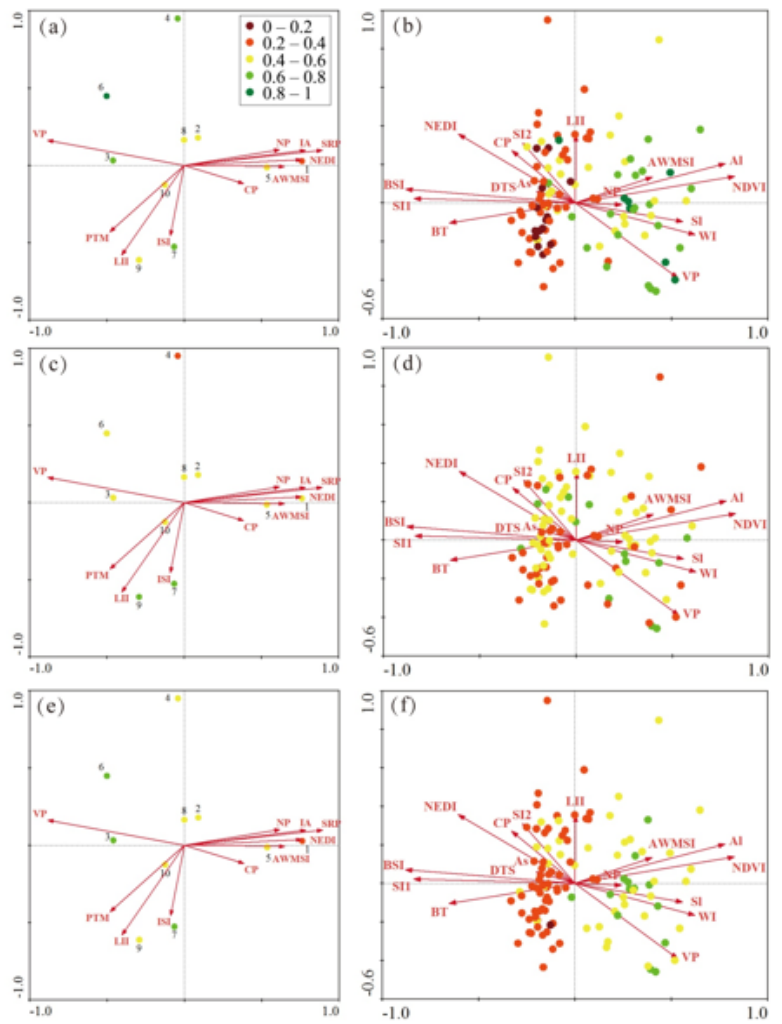

Figure 10 

of as for Fig. 6. (a), (c), and (e) refer to VHI, SHI, and VSSHI at island scale, respectively; (b), (d), and (f) denote VHI, SHI, and VSSHI at site scale, respectively. Abbreviations for the factors are the same as for Table 1.
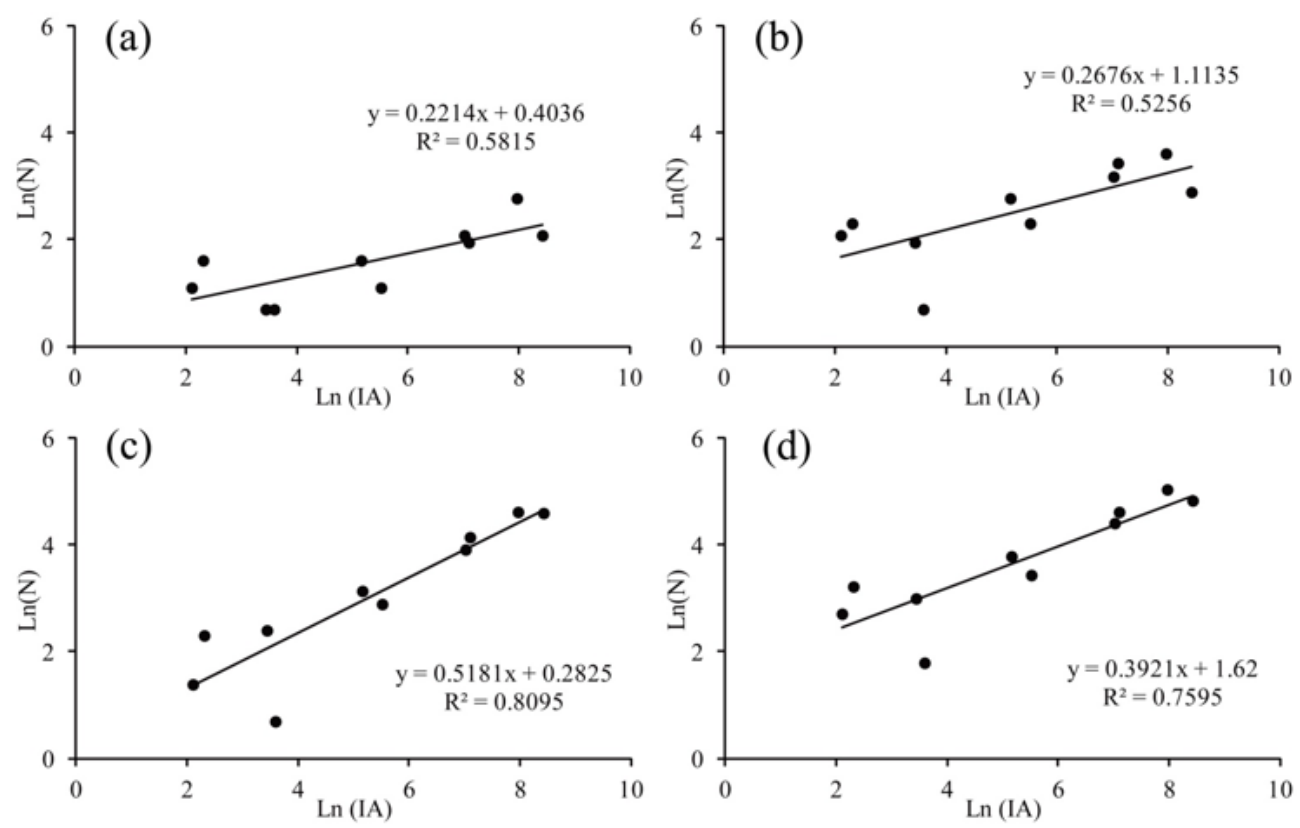

Figure 11

Island species-area relationships for different layers: (a): species in tree layer; (b): species in shrub layer; (c): species in herb layer; (d): species in all of the three layers.

\section{Supplementary Files}

This is a list of supplementary files associated with this preprint. Click to download.

- SupplementaryMaterials.doc 